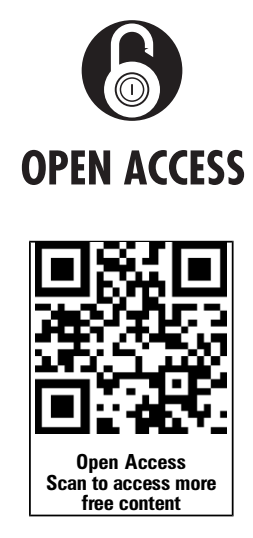

- Additional material is published online only. To view please visit the journal online (http://dx.doi.org/10.1136/ gutjnl-2014-307916)

${ }^{1}$ Antigen Presentation Research Group, Imperial College London, Northwick Park and St. Mark's Campus, Harrow, UK

${ }^{2}$ Department of Medicine, Division of Gastroenterology, Johns Hopkins University School of Medicine, Baltimore Maryland, USA

${ }^{3}$ St. Mark's Hospital, North West London Hospitals NHS Trust, Harrow, UK

\section{Correspondence to}

Professor Stella C Knight,

Antigen Presentation Research

Group, Imperial College

London, Northwick Park and

St. Mark's Campus, Level 7W

St. Mark's Hospital, Watford

Road, Harrow, HA1 3UJ, UK;

s.knight@imperial.ac.uk

Dr Xuhang Li ,

Department of Medicine

Division of Gastroenterology,

Johns Hopkins University

School of Medicine,

720 Rutland Avenue, Ross

Building Room 746, Baltimore,

Maryland, 21205, USA:

xuhang@jhmi.edu

Received 25 June 2014

Revised 21 November 2014

Accepted 27 November 2014

Published Online First

9 February 2015

\title{
Compartment-specific immunity in the human gut: properties and functions of dendritic cells in the colon versus the ileum
}

\author{
Elizabeth R Mann, ${ }^{1,2}$ David Bernardo, ${ }^{1}$ Nicholas R English, ${ }^{1}$ Jon Landy, ${ }^{1,3}$ \\ Hafid O Al-Hassi, ${ }^{1}$ Simon TC Peake, ${ }^{1,3}$ Ripple Man, ${ }^{3}$ Timothy R Elliott, ${ }^{3}$ \\ Henning Spranger, ${ }^{3}$ Gui Han Lee, ${ }^{1}$ Alyssa Parian, ${ }^{2}$ Steven R Brant, ${ }^{2}$ Mark Lazarev, ${ }^{2}$ \\ Ailsa L Hart, ${ }^{1,3}$ Xuhang Li, $^{2}$ Stella C Knight ${ }^{1}$
}

\section{ABSTRACT}

Objective Dendritic cells (DC) mediate intestinal immune tolerance. Despite striking differences between the colon and the ileum both in function and bacterial load, few studies distinguish between properties of immune cells in these compartments. Furthermore, information of gut DC in humans is scarce. We aimed to characterise human colonic versus ileal DC.

Design Human DC from paired colonic and ileal samples were characterised by flow cytometry, electron microscopy or used to stimulate $T$ cell responses in a mixed leucocyte reaction.

Results A lower proportion of colonic DC produced pro-inflammatory cytokines (tumour necrosis factor- $\alpha$ and interleukin (IL)-1 $\beta$ ) compared with their ileal counterparts and exhibited an enhanced ability to generate $\mathrm{CD}^{+} \mathrm{FoxP}^{+} \mathrm{IL}-10^{+}$(regulatory) T cells. There were enhanced proportions of CD103 ${ }^{+}$Sirp $\alpha^{-}$DC in the colon, with increased proportions of $\mathrm{CD}_{103^{+}} \mathrm{Sirp}^{+} \mathrm{DC}$ in the ileum. A greater proportion of colonic DC subsets analysed expressed the lymph-node-homing marker CCR7, alongside enhanced endocytic capacity, which was most striking in $\mathrm{CD}_{103^{+}} \mathrm{Sirp}^{+} \mathrm{DC}$. Expression of the inhibitory receptor ILT3 was enhanced on colonic DC. Interestingly, endocytic capacity was associated with $\mathrm{CD}_{103^{+}}$DC, in particular CD103+Sirp $\alpha^{+}$DC. However, expression of ILT3 was associated with $\mathrm{CD}_{103^{-}} \mathrm{DC}$. Colonic and ileal DC differentially expressed skin-homing marker CCR4 and small-bowel-homing marker CCR9, respectively, and this corresponded to their ability to imprint these homing markers on T cells.

Conclusions The regulatory properties of colonic DC may represent an evolutionary adaptation to the greater bacterial load in the colon. The colon and the ileum should be regarded as separate entities, each comprising DC with distinct roles in mucosal immunity and imprinting.

\section{INTRODUCTION}

CrossMark

To cite: Mann ER, Bernardo D, English NR, et al. Gut 2016;65: 256-270.
The GI tract is in contact with numerous commensal microbiota and diverse pathogens, and therefore a balance needs to be maintained between immunogenic and tolerogenic immune responses. Dendritic cells (DC) are antigen-presenting cells (APC) that mediate intestinal immune tolerance and ensure that inflammation does not ensue in the

\section{Significance of this study}

What is already known on this subject?

- The Gl tract is in contact with numerous commensal microbiota and food antigens, thus mechanisms to generate immune tolerance to these antigens are necessary to prevent inflammation in the healthy gut.

- Intestinal $\mathrm{CD} 103^{+}$dendritic cells (DC) generate regulatory $T$ cell (T-reg) responses in mice and comprised $C D 11 b^{+}$and $C D 11 b^{-}$DC subsets, with human equivalents being $\mathrm{CD}_{103^{+}}$Sirp $\alpha^{+}$ and $\mathrm{CD}_{103^{+}}$Sirpo ${ }^{-}$DC.

- The colon and the ileum have very different functions with a much more extensive bacterial load in the colon.

- Few studies distinguish between properties of immune cells between the colon and the ileum, and information regarding human intestinal DC in general is scarce.

\section{What are the new findings?}

- There is a lower proportion of DC producing pro-inflammatory cytokines in the human colon compared with the (paired) ileum and colonic DC exhibit an enhanced ability to generate $\mathrm{CD}^{+}{ }^{+}$ox PP3 ${ }^{+} \mathrm{IL}-10^{+} \mathrm{T}$ cells (T-reg).

- A greater proportion of colonic DC express the lymph-node-homing marker CCR7 alongside enhanced endocytic capacity for bacterial sampling; this difference was most striking in CD $103^{+}$Sirp $\alpha^{+}$DC.

- Colonic DC exhibit enhanced expression of the inhibitory receptor ILT3 associated with tolerogenic antigen-presenting cells; this expression was mainly restricted to $\mathrm{CD} 103^{-} \mathrm{DC}$.

- Colonic and ileal DC demonstrate differential abilities to imprint homing properties on stimulated T cells.

healthy gut, despite constant exposure to bacteria and other stimuli (reviewed in $^{1}$ ). The antigen sampling role of DC and macrophages, via expression of pattern recognition receptors (PRRs), enables them to determine types of immune responses that 
Significance of this study

\section{How might it impact on clinical practice in the} foreseeable future?

- The colon and the ileum contain DC with distinct roles in mucosal immunity. Targeting factors determining the inflammatory or activation state of intestinal DC within separate compartments will allow manipulation and generation of regulatory DC aimed at immunomodulatory therapy for inflammatory disease with tissue compartmentalisation.

are generated against a variety of intestinal antigens. DC are unique in their ability to drive primary T cell responses; ${ }^{2}$ in the gut, primary $\mathrm{T}$ cell responses directed against intestinal antigens are generated in the mesenteric lymph nodes (MLN) and Peyer's patches (PP). Intestinal DC from the gut lamina propria (LP) recognise and respond to bacteria and bacterial products from the gut lumen, transport bacterial antigens into $\mathrm{MLN}^{3}{ }^{4}$ and maintain the delicate balance in the gut between immunogenicity against invading pathogens and tolerance of the commensal microbiota (reviewed in ${ }^{15}$ ). Another property of DC is their ability to imprint homing properties on $\mathrm{T}$ cells that they stimulate in lymphoid tissue, in order to localise immune responses to specific tissues. ${ }^{6-8}$

Intestinal DC in the steady state are generally hyporesponsive to toll-like receptor (TLR) ligation, ${ }^{9} 10$ constitutively produce the anti-inflammatory cytokine interleukin (IL)- $10^{11}$ and maintain immune tolerance in the gut by generation and maintenance of regulatory $\mathrm{T}$ cell (T-reg) responses directed against food antigens and commensal bacteria. ${ }^{12}{ }^{13}$ This process prevents unnecessary inflammation and hypersensitivity. In mice, the ability of gut DC to generate gut-specific T-reg is enhanced in the CD103 ( $\alpha_{\mathrm{E}}$ integrin) ${ }^{+}$DC subset. CD103 ${ }^{+}$DC migrate to MLN in afferent lymph, ${ }^{14}{ }^{15}$ and in the steady state this constitutive migration generates T-reg responses against harmless luminal antigens and establishes oral tolerance. ${ }^{1}{ }^{12-14}$ Human studies involving DC isolated from MLN indicate that some of the unique functional properties of intestinal $\mathrm{CD} 103^{+} \mathrm{DC}$ in mice are conserved in humans. ${ }^{14}{ }^{16}$ Intestinal CD103+ $\mathrm{DC}$ in both mice and humans express indoleamine 2,3-dioxygenase (IDO), an enzyme which enhances T-reg development and that is required for the establishment of immune tolerance in the gut. ${ }^{17}$ IDO is induced by IL-27 at intestinal sites and contributes to growth inhibition of intestinal bacteria. ${ }^{18}$

$\mathrm{CD} 103^{+} \mathrm{DC}$ can be further characterised by their coexpression of CD11b; CD $103^{+} \mathrm{CD} 11 \mathrm{~b}^{+}$and $\mathrm{CD} 103^{+} \mathrm{CD} 11 \mathrm{~b}^{-}$DC require different genetic factors for their development, ${ }^{19}$ and although both subsets can induce $T$ cell responses of both inflammatory and tolerising natures, recent studies suggest these DC subsets may have distinct roles in intestinal immune homeostasis (reviewed in $\left.^{20}{ }^{21}\right)$. However, the specific functions of these DC subsets in immune tolerance in particular are unclear. Equivalent subsets of $\mathrm{CD}_{103}{ }^{+} \operatorname{Sirp} \alpha^{+}\left(\mathrm{CD} 11 \mathrm{~b}^{+}\right)$and $\mathrm{CD}_{103}{ }^{+} \operatorname{Sirp}^{-}\left(\mathrm{CD} 11 \mathrm{~b}^{-}\right)$DC in the human small intestine (ileum) have recently been identified, ${ }^{22-24}$ but whether these subsets are present in the human colon had not previously been demonstrated.

The colon and the ileum have different functions, the main function of the colon being extraction of water and salt from solid wastes and the ileum being absorption of nutrients and minerals in food. The bacterial load in the ileum ranges from
$10^{4}$ to $10^{8} \mathrm{CFU} / \mathrm{mL}$; however, the colon is much more heavily colonised with a bacterial load of $10^{11}$ to $10^{12} \mathrm{CFU} / \mathrm{mL} .^{25} 26$ Despite these differences both in function and bacterial colonisation, there are few studies that distinguish between properties of immune cells in these compartments. Furthermore, information regarding properties of intestinal DC in either compartment in humans is scarce, and the majority of murine data refers to the ileum or organised lymphoid tissue.

Identification of intestinal DC is controversial; different laboratories use different markers to identify DC. Many different cell types in the gut mucosa express CD11c and HLA-DR/major histocompatibility complex (MHC) class II, which various groups use as a basis for DC characterisation. However, other studies have indicated that most of these cells are not genuine DC. ${ }^{27}{ }^{28} \mathrm{DC}$ expressing $\mathrm{CX}_{3}$-chemokine receptor $1\left(\mathrm{CX}_{3} \mathrm{CR} 1\right){ }^{29}$ a molecule essential for the ability of cells to extend transepithelial projections into the gut lumen, ${ }^{30}$ have been described in mice ${ }^{30}$ but the identity of murine $\mathrm{CD} 11 \mathrm{c}^{+} \mathrm{CX}_{3} \mathrm{CR} 1^{+}$cells as bona fide DC has been challenged by studies demonstrating $M \Phi$-like vacuolar systems of these ' $\mathrm{DC}$ '31 and their poor ability to drive naive Tcell stimulation and differentiation, ${ }^{31}{ }^{15}$ as well as their inability to migrate to MLN. ${ }^{15}$ It has recently been determined that all CX $\mathrm{CR}_{3} 1^{\mathrm{hi}}$ MHC class $\mathrm{II}^{+}$cells in the murine gut are in fact macrophages. Within a smaller population of $\mathrm{CX}_{3} \mathrm{CR} 1^{\text {int }}$ cells, only a fraction of these are bona fide DC. ${ }^{29}$ In this study, we have successfully characterised DC from the human colon and ileum. We find that DC derived from the colon exhibit enhanced regulatory properties and functions compared with their paired, ileal counterparts. Furthermore, we show differences between the proportions and functions of $\mathrm{CD}_{103}{ }^{+} \mathrm{Sirp}^{+}$and $\mathrm{CD} 103^{+} \mathrm{Sirp}^{-} \mathrm{DC}$ in the human colon and ileum. We demonstrate that the enhanced regulatory properties of total colonic DC are due to intrinsic differences in specific DC subsets rather than shifts in proportions of regulatory DC populations between colonic and ileal compartments.

This study demonstrates that the colon and the ileum each comprised DC with distinct roles in mucosal immune homeostasis and imprinting, and should be regarded as separate entities.

\section{MATERIALS AND METHODS}

\section{Tissues and cells}

Intestinal biopsies were obtained from the colon and the terminal ileum in each patient, at colonoscopy from healthy controls, following informed consent. These patients had macroscopically and histologically normal intestines. Biopsies were collected in complete medium. Cells were obtained from biopsy tissue by a cell migration/'walkout' assay during overnight incubation $\left(37^{\circ} \mathrm{C}\right.$, $5 \% \mathrm{CO}_{2}$, high humidity). DC from 'walkout' cells were identified as $\mathrm{CD}_{4}{ }^{+} \mathrm{SSC}^{\text {lo-med }}$ HLA-DR ${ }^{+}$lineage cocktail (CD3/CD14/ CD16/CD19/CD34) ${ }^{-}$CD11 ${ }^{+}$CD $64^{-}$cells by flow cytometry (figure 1). Confirmatory experiments were carried out to compare CD103 expression on colonic DC using the 'walkout' method compared with collagenase digestion; there were no differences in the proportion of $\mathrm{CD} 103^{+}$DC using these two methods (see online supplementary figure S1). Confirmatory experiments were also carried out to confirm CD64 antibody staining is positive on HLA-DR ${ }^{+} \mathrm{Lin}^{\text {med }}$ cell populations (see online supplementary figure S2). DC were analysed for surface phenotype, cytokine production and phagocytosis capacity. In other experiments, total walkout cells were enriched for DC by centrifugation $(600 \mathrm{~g}, 15 \mathrm{~min}$ at room temperature) over NycoPrep and used for $\mathrm{T}$ cell stimulation. These intestinalderived DC have been characterised previously as functional intestinal DC. ${ }^{32}$ 
Figure 1 Expression of CD103 and Sirpo on human colonic and ileal dendritic cells (DC). (A) Identification of human gut DC according to FACS dot plot of lineage cocktail (CD3/CD14/ CD16/CD19/CD34) versus HLA-DR (following identification of live cells as CD45 ${ }^{+}$dead cell exclusion dye ${ }^{-}$cells) and subsequent CD11c versus CD64 dot plots. (B) Following DC identification as $\mathrm{HLA}-\mathrm{DR}^{+}$lineage cocktail ${ }^{-}$CD11 $\mathrm{c}^{+} \mathrm{CD} 64^{-}$cells, expression of CD103 and Sirp $\alpha$ was analysed. Dot plot quadrants were set according to comparison with isotype-matched controls; FACS dot plots demonstrating expression of CD103 and Sirp $\alpha$ on human colonic and ileal DC. (C) Summary graph demonstrating proportions of $\mathrm{CD}_{103^{+}} \mathrm{Sirp}^{+}, \mathrm{CD} 103^{+}$Sirp $\alpha^{-}$and $\mathrm{CD}_{103^{-}}$Sirpo $\alpha^{+} \mathrm{DC}$ in the human colon and ileum $(n=12)$ (D) Summary graphs showing proportions of $\mathrm{CD}_{103^{+}} \mathrm{Sirp}^{+}$ and $\mathrm{CD}_{103^{+}}$Sirp $\alpha^{-} \mathrm{DC}$ in all experiments $(n=12)$. Paired t test was applied in all cases: ${ }^{*} p<0.05$; ${ }^{* *} p<0.01 ;{ }^{* * *} p<0.001$.

A Colon Gated on $\mathrm{CD} 5^{+} \mathrm{SSC}^{\mathrm{lo-med}}$ cells

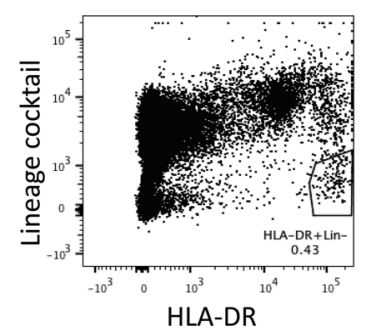

Ileum
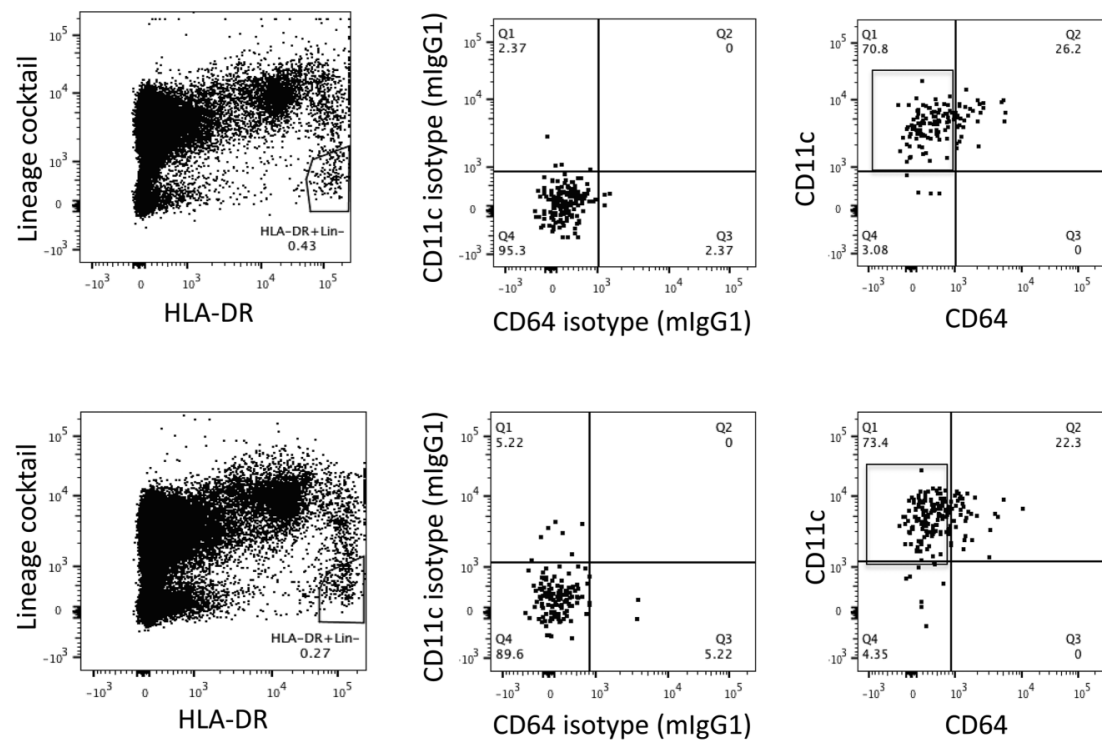

B

Colon

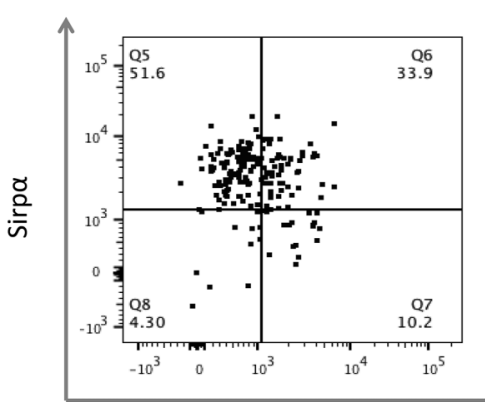

Ileum

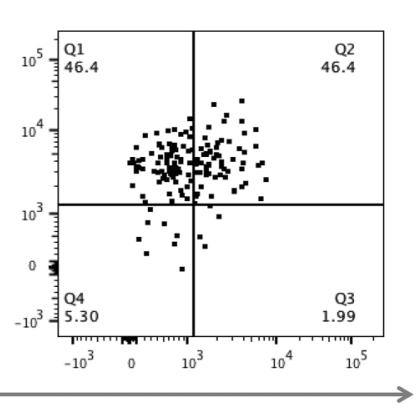

CD103

C

DC subsets in the human gut

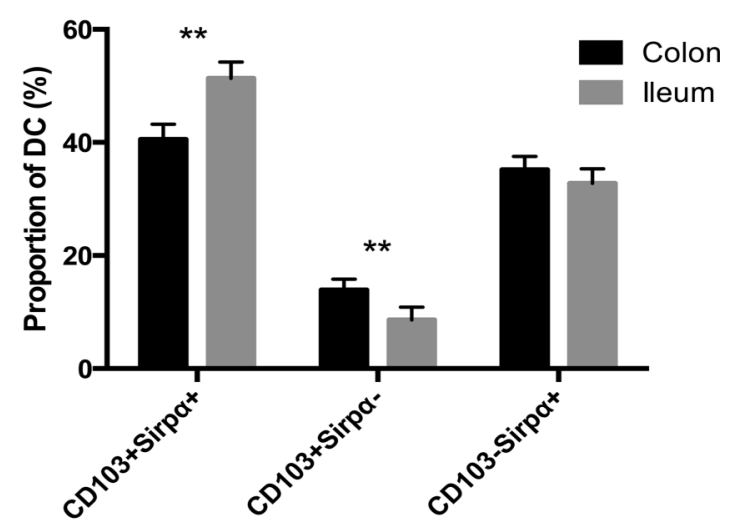

D

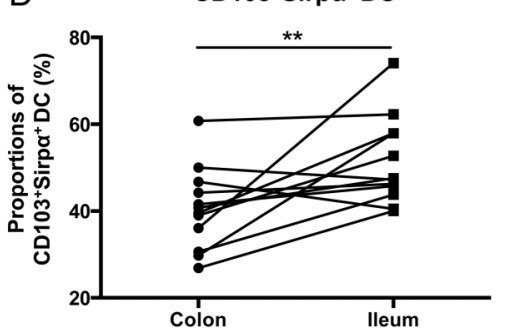

CD103+Sirpa-DC

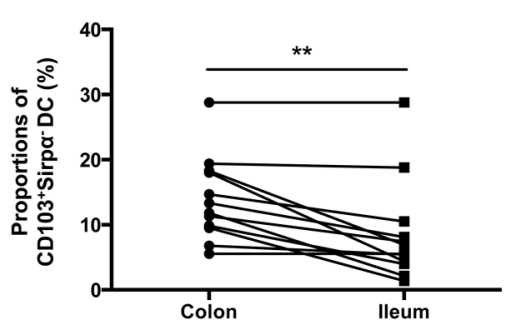


Human peripheral blood was collected from healthy volunteers with no known autoimmune or inflammatory diseases, allergies or malignancies, following informed consent.

\section{Enrichment of $\mathrm{CD}^{+}$naive T cells}

Peripheral blood mononuclear cells (PBMC) from healthy control blood were obtained by centrifugation over Ficoll-Paque Plus (Amersham Biosciences, Chalfont St. Giles, UK). PBMC were suspended in MiniMACS buffer (phosphate-buffered saline (PBS) containing $0.5 \%$ bovine serum albumin and $2 \mathrm{mM}$ ethylenediaminetetraacetic acid) and $\mathrm{CD}^{+}{ }^{+}$naive $\mathrm{T}$ cells were enriched by depletion of $\mathrm{CD} 14^{+}, \mathrm{CD} 19^{+}, \mathrm{HLA}-\mathrm{DR}{ }^{+}, \mathrm{CD} 8^{+}$ and $\mathrm{CD}_{45 \mathrm{RO}^{+}}$cells with immunomagnetic beads (Miltenyi Biotech, Bisley, UK) following the manufacturer's instructions. Purity was $>95 \%$ in all cases.

\section{T cell proliferation assay}

Carboxyfluorescein succinimidyl ester (CFSE, Invitrogen, UK)-labelled $\mathrm{CD}^{+}{ }^{+}$naive $\mathrm{T}$ cells $\left(4 \times 10^{5} /\right.$ well $)$ were incubated for 5 days in U-bottomed 96-well microtiter plates with enriched allogeneic DC at $0 \%, 1 \%, 2 \%$ or $3 \%$ in a mixed leucocyte reaction. Cells were recovered and $\mathrm{CFSE}^{\text {lo }}$ proliferating cells identified and quantified by flow cytometry.

\section{Antibody labelling}

Monoclonal antibodies with the following specificities and conjugations were used: CD103-fluorescein isothiocyanate (FITC) (BER-ACT8), IL-12 FITC/PE (C11.5), T-bet-PE (4B10), FoxP3-PE (259D/C7), IL-17A-PE (SCPL1362), integrin $\beta 7-P E$ (FIB504), CD34-PeCy5 (581), CD4-PeCy5 (RPA-T4), HLA-DRAPC (G46-6), IFN- $\gamma$-APC (B27), IL-10-APC (JES5-19FI) and IL-4-PeCy7 (8D4-8) were purchased from BD Biosciences (Oxford, UK); TLR2-FITC (TLR2.3), TLR4-FITC (HTA125), CD40-FITC/PE (LOB7/6), CD3-PeCy5 (S4.1), CD14-PeCy5 (TUK4), CD16-PeCy5 (3G8), CD19-PeCy5 (SJ25-C1) and tumour necrosis factor (TNF)- $\alpha$-APC (MP9-20A4) were purchased from AbD Serotec (Oxford, UK); TNF- $\alpha$-FITC (MAb11), IL-1ß-FITC (B-A15), CD68-PE (Y1/82A) and IL-22PeCy7 (22URTI) were purchased from eBioscience (Hatfield, UK); CX3CR1-PE (528728), ILT3-PE (293263), TGFß1-PE (27232), CCR9-PE (248621), CCR7-PE/PeCy7 (2H4) and CCR4-APC (205410) were purchased from R\&D Systems (Abingdon, UK); CD64-PeCy7 (10.1) was purchased from Biolegend (London, UK). Appropriate isotype-matched control antibodies were purchased from the same manufacturers. After the staining, cells were fixed with $1 \%$ paraformaldehyde in $0.85 \%$ saline.

\section{Cytokine analysis}

The intracellular cytokine production by DC was measured by comparing cells incubated without monensin (controls) from those incubated in the presence of monensin for $4 \mathrm{~h}$.

\section{Flow cytometry and data analysis}

Data were acquired on FACSCanto II and LSR II machines (BD Biosciences) and analysed using FlowJo (Treestar).

\section{Endocytic activity of DC}

Endocytic activity of DC was determined by uptake of FITC-dextran (molecular weight $=40 \mathrm{kDa}$ ) (Sigma-Aldrich, UK). Briefly, cells were incubated with $1 \mathrm{mg} / \mathrm{mL}$ FITC-dextran for $30 \mathrm{~min}$ at either 37 or $4^{\circ} \mathrm{C}$ (on ice; internal control), and then washed in PBS. Surface staining for flow cytometry was then performed.

\section{Electron microscopy}

Tissue was fixed in 3\% glutaraldehyde and 1\% osmium tetroxide, then washed and block stained with $2 \%$ uranyl acetate. The samples were then dehydrated using an acetone gradient and gradually infiltrated with araldite resin. Sections $(100 \mathrm{~nm})$ were cut on a Reichert-Jung Ultracut E microtome and collected on a 200 mesh copper grid. The grid was stained with Reynold's lead citrate, carbon coated and visualised using a JEOL 1200 EX electron microscope.

\section{Statistical analysis}

Two-way and one-way repeated measures analysis of variance and two-tailed paired tests were applied as stated in the figure legends. In the case of multiple comparisons, subsequent ad hoc Bonferroni correction was applied. $\mathrm{p}<0.05$ was considered statistically significant.

\section{RESULTS}

\section{Characterisation of $\mathrm{CD} 103^{+} \mathrm{DC}$ subsets in the human colon} and ileum

Human intestinal DC were identified as $\mathrm{HLA}_{-} \mathrm{DR}^{+} /$lineage cocktail (CD3/CD14/CD16/CD19/CD34) ${ }^{-} \mathrm{CD}_{11 c^{+}} \mathrm{CD}^{-} 4^{-}$cells by flow cytometry (figure 1A). Identifying human intestinal DC in this manner enabled analysis, characterisation and comparison of DC within separate intestinal compartments. In mice, regulatory DC capable of generating T-reg responses express CD103 and migrate to lymphoid tissue. ${ }^{1}{ }^{12-14}$ However, the regulatory functions of specific intestinal $\mathrm{CD}_{103^{+}}$DC subsets in mice, including $\mathrm{CD} 03^{+} \mathrm{CD} 11 \mathrm{~b}^{-}$and $\mathrm{CD} 103^{+} \mathrm{CD} 11 \mathrm{~b}^{+} \mathrm{DC}$, are unclear. Recently identified equivalent subsets in the human small intestine (ileum) have been determined including $\mathrm{CD} 103^{+} \mathrm{Sirp}^{+} \mathrm{DC}$ (representing murine $\mathrm{CD}_{103}{ }^{+} \mathrm{CD} 11 \mathrm{~b}^{+} \mathrm{DC}$ ) and $\mathrm{CD} 103^{+}$Sirpo ${ }^{-}$DC (representing murine $\left.\mathrm{CD} 103^{+} \mathrm{CD} 11 \mathrm{~b}^{-} \mathrm{DC}\right) .^{22-24}$ However, such subsets in the human colon previously remained to be characterised.

To this end, we compared expression of CD103 and Sirpo on human gut DC within both colonic and ileal compartments. Both human colonic and ileal DC expressed CD103, and the majority of these CD $103^{+}$DC co-expressed Sirp $\alpha$ in both cases (figure $1 \mathrm{~B}, \mathrm{C}$ ). However, there was a greater proportion of $\mathrm{CD}_{103}{ }^{+} \mathrm{Sirp}^{+} \mathrm{DC}$ in the ileum, alongside enhanced proportions of $\mathrm{CD} 103^{+}$Sirp $\alpha^{-} \mathrm{DC}$ in the colon (figure 1C, D). There was no change in the proportions of $\mathrm{CD}_{103^{-} \mathrm{Sirp} \alpha^{+} \mathrm{DC}}$ between colonic and ileal compartments (figure 1C). Due to the small proportions and numbers of $\mathrm{CD}_{103}{ }^{+} \mathrm{Sirp} \alpha^{-} \mathrm{DC}$ in all cases, further phenotypic analysis of this DC subset was not possible. These results indicate differences in the proportions of $\mathrm{CD}_{103}{ }^{+}$DC subsets, but not $\mathrm{CD} 103^{-}$DC exist between colonic and ileal compartments of the human gut.

\section{Enhanced expression of the lymph-node-homing marker CCR7 on human CD103 ${ }^{+}$Sirpa ${ }^{+}$DC in the colon}

In mice, CD $103^{+}$DC migrate to MLN in afferent lymph. ${ }^{14} 15 \mathrm{In}$ the steady state, this constitutive migration generates tolerogenic $\mathrm{T}$ cell responses against harmless luminal antigens and establishes oral tolerance. ${ }^{1{ }^{12-14}}$ Both CD103 ${ }^{+}$and CD103- DC from the colon displayed enhanced CCR7 expression (figure 2A). Furthermore, a striking difference in proportions of CCR7 expression was observed upon comparison of $\mathrm{CD}_{103}{ }^{+} \mathrm{Sirp \alpha}^{+} \mathrm{DC}$ between the colon and the ileum, with a greater proportion of $\mathrm{CCR}^{+} \mathrm{DC}$ within this DC subset in the colon (figure $2 \mathrm{~B}$; there were not enough cell numbers to analyse CCR7 expression on $\left.\mathrm{CD}_{103}{ }^{+} \mathrm{Sirp} \alpha^{-} \mathrm{DC}\right)$. These data suggest a more migratory role for colonic DC compared with their ileal counterparts. 
Figure 2 Expression of CCR7 on human colonic and ileal dendritic cells (DC) subsets. (A) FACS dot plots demonstrating expression of CD103 and co-expression of lymph-nodehoming marker CCR7 on colonic and ileal DC. Dot plot quadrants were set according to comparison with isotypematched controls. Summary graphs representing CCR7 on all $D C, C D 103^{+}$ $D C$ and $C D 103^{-} D C$ ( $n=6$ in all cases). (B) FACS dot plots demonstrating expression of CCR7 on $\mathrm{CD}_{103^{+} \text {Sirp }}{ }^{+}$ DC on colonic and ileal DC and summary graph representing CCR7 on

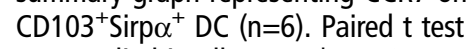
was applied in all cases: * $p<0.05$; ${ }^{* *} p<0.01 ;{ }^{* * *} p<0.001$.
A

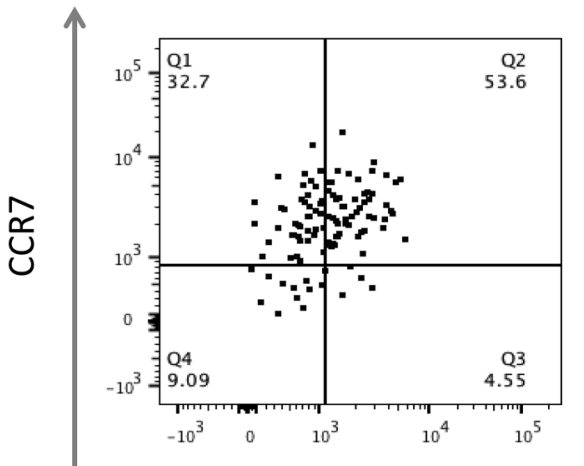

Ileum

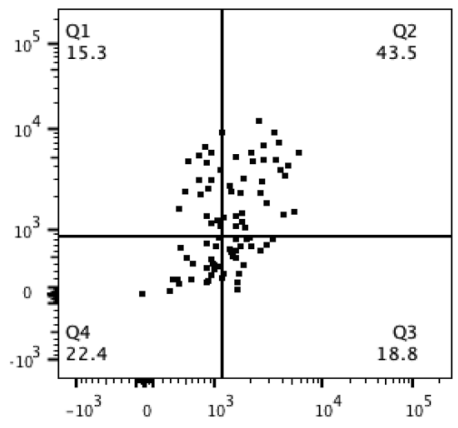

CD103

B Gated on $\mathrm{CD}_{103^{+}}$Sirpa $^{+} \mathrm{DC}$

Colon

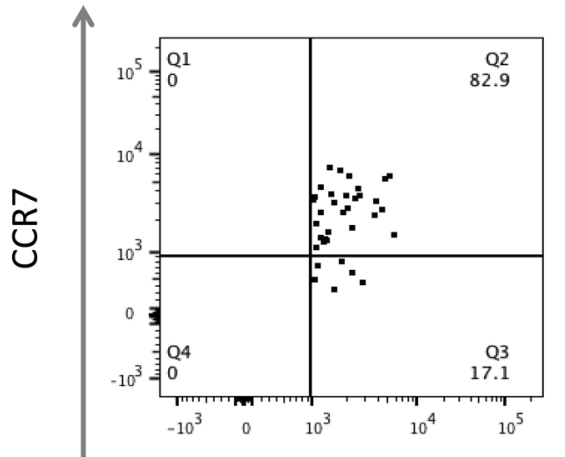

CCR7 on CD103- DC

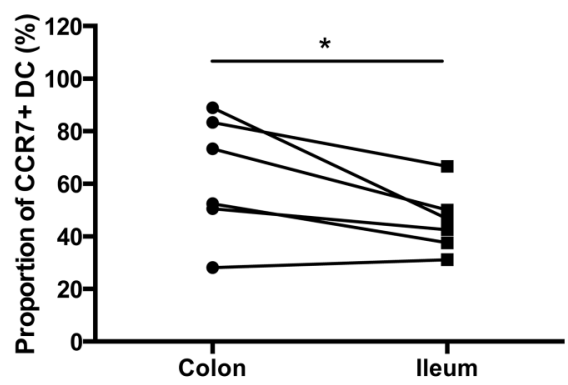

lleum

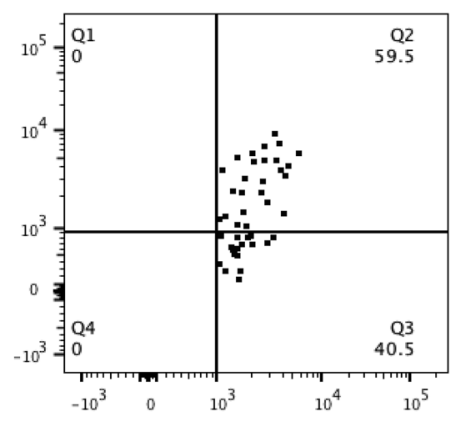

CD103

CCR7 on $\mathrm{CD}_{103^{+}} \mathrm{Sirpa}^{+} \mathrm{DC}$

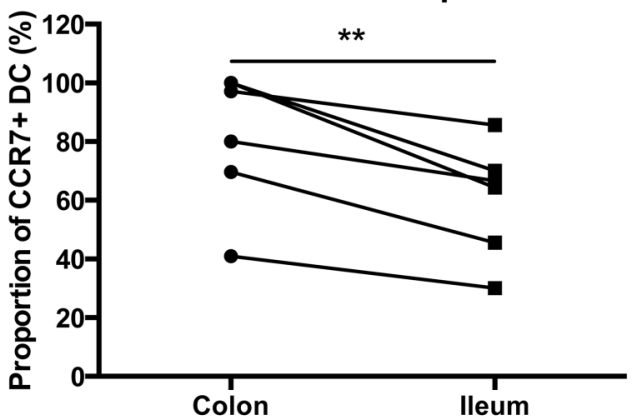


Human colonic DC display enhanced endocytic capacity compared with equivalent ileal DC

We next wanted to determine whether the increased migratory potential of DC in the colon (via CCR7 expression) corresponded with differences in antigen uptake (endocytic) capacity. To this end, we tested the ability of human intestinal DC to endocytose FITC-dextran. We found that a greater proportion of total DC from the colon displayed an endocytic capacity compared with their ileal counterparts (figure 3A, B). Interestingly, in both intestinal compartments, the majority of FITC-dextran ${ }^{+}$DC were CD $103^{+}$(figure 3A, D).

However, enhanced endocytic function was observed in both $\mathrm{CD}_{103^{+}}$and CD103- colonic DC subsets compared with their ileal counterparts (figure 3A, D). Analysis of $\mathrm{CD} 103^{+} \mathrm{Sirp \alpha}{ }^{+}$ DC showed enhanced endocytic capacity by this DC subset in the colon compared with their ileal equivalents (figure 3C, D). Furthermore, $\mathrm{CD} 103^{+} \mathrm{Sirp} \alpha^{+} \mathrm{DC}$ had a greater endocytic function compared with other DC subsets in both colonic and ileal compartments (figure 3D).
Thus, taken with data above demonstrating enhanced expression of CCR7 by colonic CD $103^{+}$Sirp $\alpha^{+}$DC in particular, these data strongly suggest a role for antigen-sampling and steady-state migration to lymphoid tissue by this DC subset. Furthermore, the enhanced endocytic capacity of DC subsets in the colon suggests a greater role for colonic DC in this process.

\section{Higher levels of the inhibitory receptor ILT3 on colonic DC}

ILT3 is an inhibitory receptor expressed on myeloid APC. ${ }^{33}$ High levels of ILT3 expression have been shown to render APC tolerogenic, ${ }^{34} 35$ with at least some of the inhibitory effects of ILT3 being mediated through suppression of T cell responses. ${ }^{3637}$ To determine whether there was a difference in the potential inhibitory properties of colonic and ileal DC subsets, we determined the expression of ILT3 on DC from these compartments. There was a greater proportion of total DC from the colon expressing ILT3 compared with their ileal counterparts (figure 4A). However, levels of expression of ILT3 per cell as assessed by fluorescence intensity were not

A

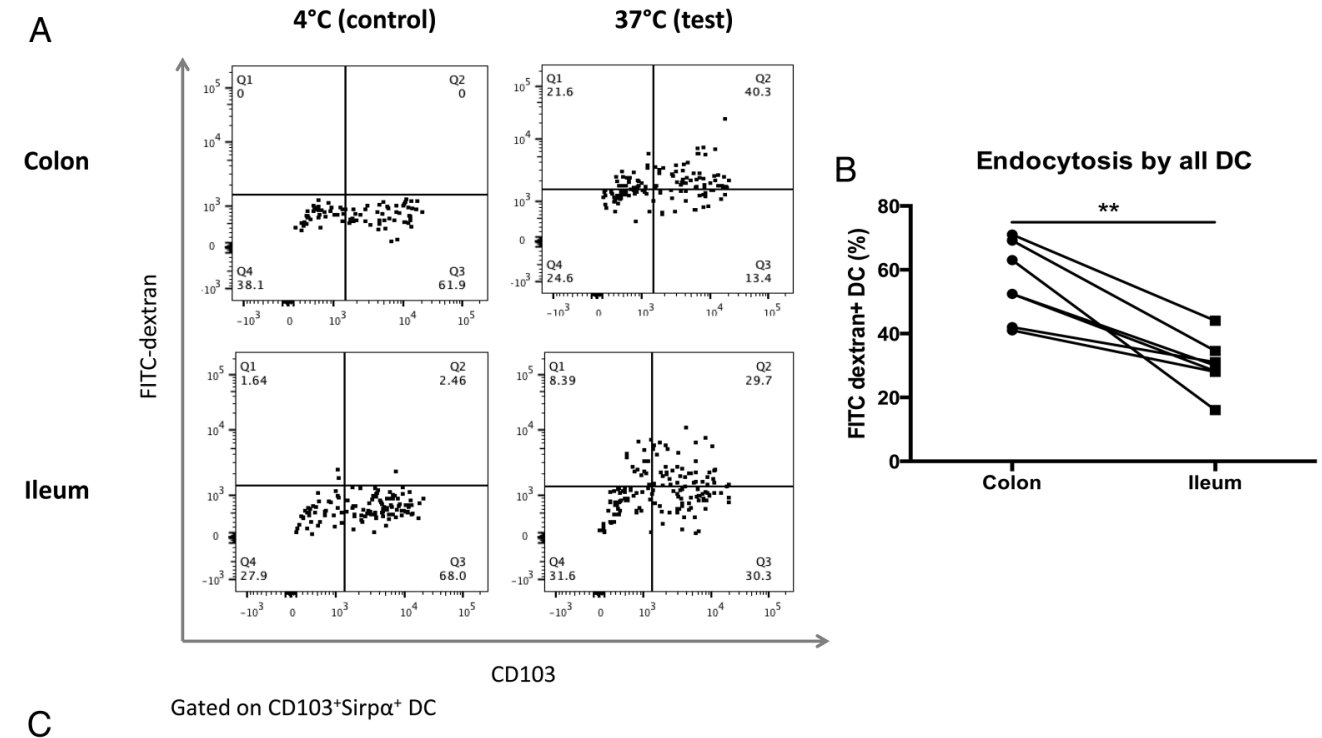

$37^{\circ} \mathrm{C}$ (test)

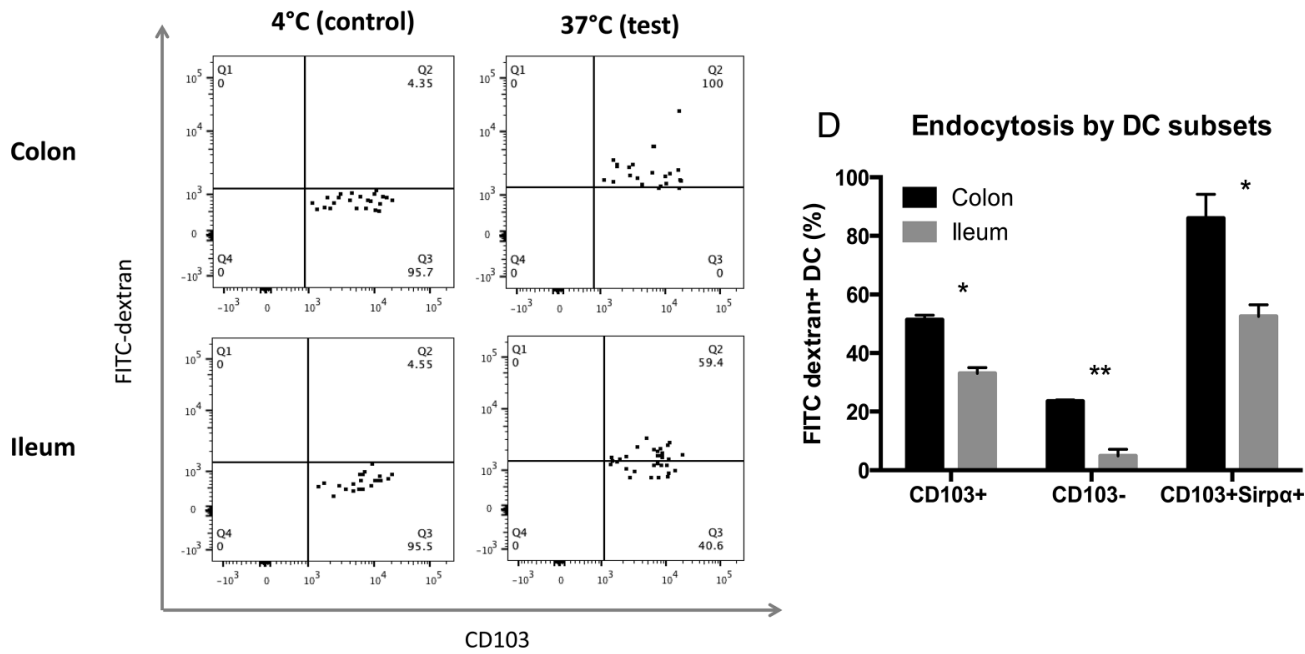

Figure 3 Uptake of fluorescein isothiocyanate (FITC)-dextran as a measure of endocytosis by colonic and ileal dendritic cells (DC). (A) FACS dot plots demonstrating endocytosis of FITC-labelled dextran over 30 min at $4{ }^{\circ} \mathrm{C}$ (control) and $37^{\circ} \mathrm{C}$ (test) by colonic and ileal CD103 ${ }^{+}$and $\mathrm{CD} 103^{-}$DC. Dot plot quadrants were set according to comparison with control staining $\left(4^{\circ} \mathrm{C}\right)$ as demonstrated. (B) Summary graph demonstrating FITC-dextran uptake by total DC $(n=6)$. (C) FACS dot plots demonstrating endocytosis of FITC-labelled dextran by $\mathrm{CD}_{103^{+}}$Sirpo ${ }^{+} \mathrm{DC}$ at $4^{\circ} \mathrm{C}(\mathrm{control})$ and $37^{\circ} \mathrm{C}$ (test) within colonic and ileal compartments $(n=3)$. (D) Summary graph representing FITC-dextran uptake by CD103 ${ }^{+}, C_{103^{-}}$and $C D 103^{+}$Sirpo ${ }^{+}$DC within colonic and ileal compartments $(n=3)$. Paired t test was applied in all cases: ${ }^{*} p<0.05 ;{ }^{* *} p<0.01 ;{ }^{* *} p<0.001$. 
significantly different between total colonic and ileal DC (figure 4B).

Upon analysis of specific DC subsets, we determined that CD103- DC were the major DC subset expressing ILT3, with both proportions of positive cells and levels of expression per cell being greater than that of $\mathrm{CD} 103^{+} \mathrm{DC}$ in both intestinal compartments (figure 4A, C). Strikingly, proportions of $\mathrm{CD}_{103^{-}} \mathrm{DC}$ expressing ILT3 were enhanced in the colon, alongside enhanced levels of expression of ILT3 per cell (figure 4D). However, proportions of both $\mathrm{CD}_{103}{ }^{+} \mathrm{DC}$ (figure 4E) and CD $103^{+}$Sirp $\alpha^{+} \mathrm{DC}$ (figure 4F) expressing ILT3 were also enhanced in the colon, although there was no change in the levels of ILT3 expression per cell compared with ileal DC in these DC subsets. Given the regulatory properties associated with this receptor, the enhanced expression on colonic DC supports a more regulatory role for these cells versus their ileal counterparts.

\section{DC maturation and activation is equivalent in the colon and} the ileum

Intestinal DC characteristically express low levels of TLRs compared with blood DC, thought to contribute to hyporesponsiveness to the gut microbiota in the steady state. ${ }^{11}$ To determine potential differences in colonic versus ileal ability to sense bacteria and microbial products, we analysed expression of TLRs 2 and 4, and also expression of DC activation marker CD40 (a marker that we have to enhance on gut DC in inflammation ${ }^{38}$ ). We found that there were no differences in expression of these molecules, comparing DC from colonic and ileal tissue (figure 5A), suggesting there were no differences in DC maturation and activation between colonic and ileal compartments. To further analyse the maturation state of DC, we used electron microscopy (EM) to analyse DC morphology. Immature and mature DC, as assessed by length of veiled protrusions, ${ }^{39}$ were detected from the colon and the ileum, as were macrophage-like cells with an extensive vacuolar network. These observations demonstrated there were no differences in proportions of mature DC or macrophage-like cells. However, there was an enhanced proportion of morphologically immature DC in the ileum (figure 5B).

\section{Enhanced proportion of pro-inflammatory cytokine producing DC in the ileum}

Given the different functions and antigenic load of the colon and the ileum, we investigated whether immunological functions of these compartments differed, specifically regarding DC. Arguably,
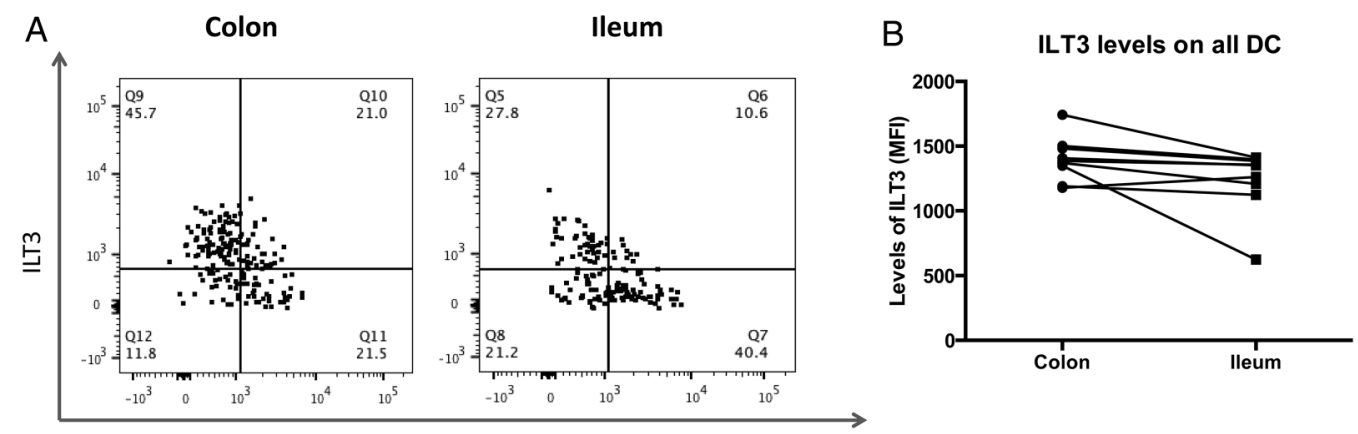

CD103
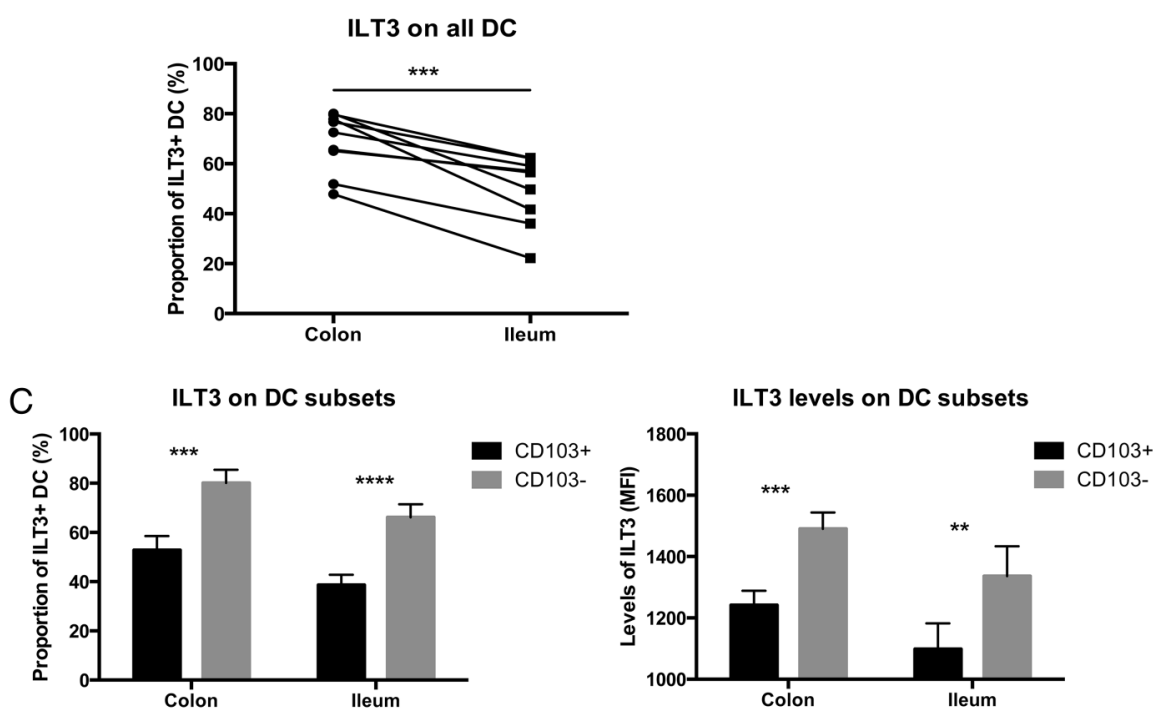

Figure 4 Expression of the inhibitory receptor ILT3 on colonic and ileal dendritic cells (DC). (A) FACS dot plots demonstrating expression of ILT3 on colonic and ileal $\mathrm{CD}_{103^{+}}$and $\mathrm{CD} 103^{-} \mathrm{DC}$. Dot plot quadrants were set according to isotype-matched controls. Summary graph demonstrating proportions of ILT3 ${ }^{+}$(total) DC from colon and ileum $(n=8)$. (B) Summary graph demonstrating levels of expression (mean fluorescence intensity (MFI)) of ILT3 on colonic and ileal DC $(n=8)$. (B) Summary graphs representing proportion of ILT3 ${ }^{+}$DC and levels of ILT3 expression (MFI) on CD103 ${ }^{+}$ compared with $C D 103^{-}$DC $(n=8)$ in the colon and the ileum. (D) Summary graphs representing the proportion of CD103 ${ }^{-}$DC expressing ILT3 and levels of ILT3 expression on CD103- DC $(n=8)$. (E) Summary graphs representing the proportion of CD103 ${ }^{+}$DC expressing ILT3 and levels of ILT3

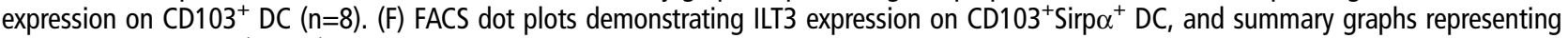

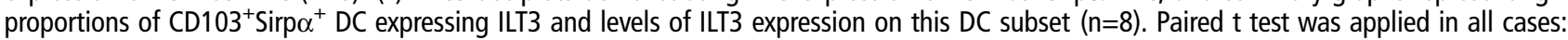
${ }^{*} \mathrm{p}<0.05 ;{ }^{* *} \mathrm{p}<0.01 ;{ }^{* * *} \mathrm{p}<0.001$. 
D

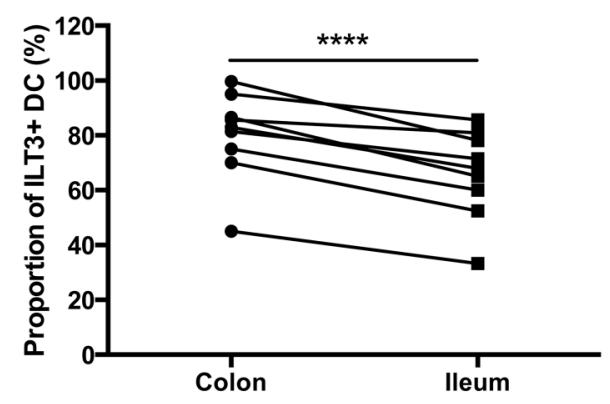

E

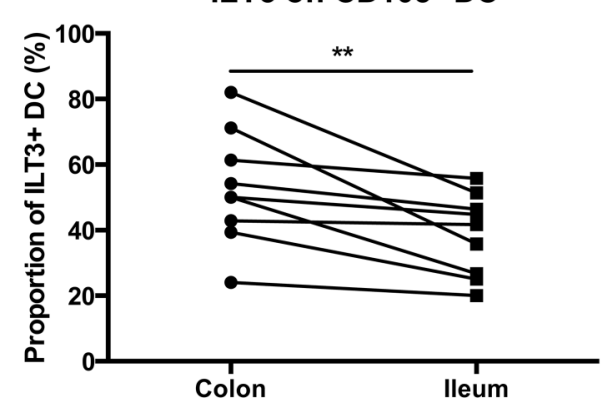

\section{ILT3 levels on CD103-DC}

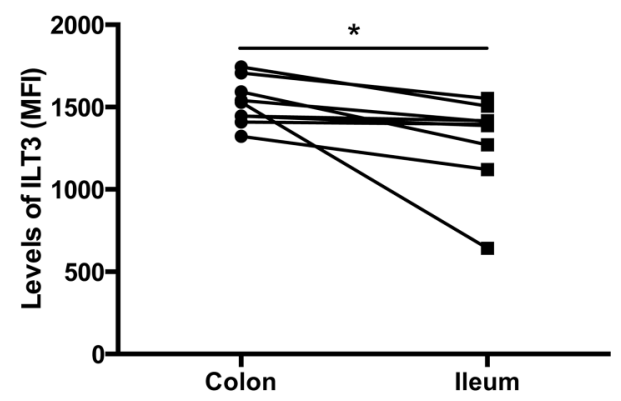

ILT3 levels on CD103+ DC

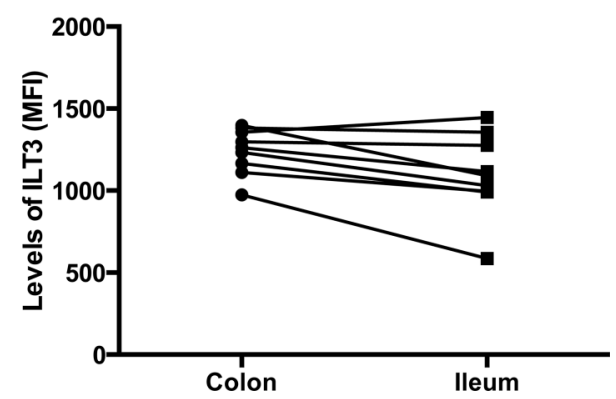

F $\quad$ Gated on $\mathrm{CD} 103^{+}$Sirpa $\alpha^{+}$DC

Colon

lleum

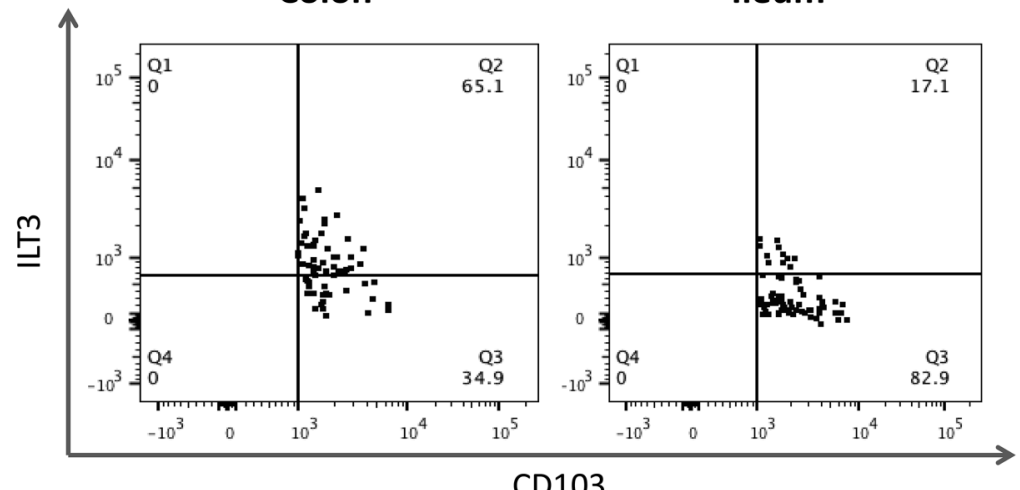

CD103

ILT3 on $\mathrm{CD} 103^{+}$Sirpa $^{+} \mathrm{DC}$

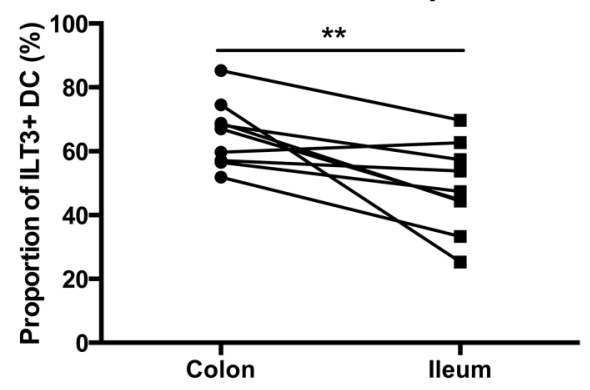

ILT3 levels on $\mathrm{CD}_{103}+$ Sirpa $^{+} \mathrm{DC}$

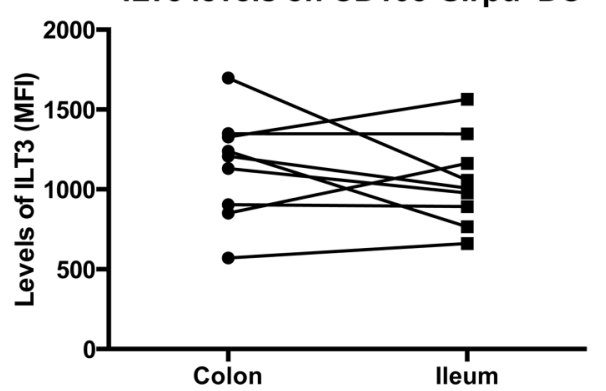

Figure 4 Continued.

the most important function of DC is their unique ability to generate primary $\mathrm{T}$ cell responses. DC ability to polarise specific types of $\mathrm{T}$ cell responses is in part due to DC production of specific $\mathrm{T}$ cell polarising cytokines. To this end, prior to analysis of DC ability to generate types of $\mathrm{T}$ cell responses, we determined whether there were differences between colonic and ileal DC in the production of regulatory or pro-inflammatory cytokines.
Intracellular cytokine production by total DC within colonic and ileal compartments following monensin incubation was detected via comparison to non-monensin-treated controls (figure 6A). Although production of all measured cytokines was low from all DC aside from TGF- $\beta$ and TNF- $\alpha$ (figure 6B), a greater proportion of ileal DC produced the pro-inflammatory cytokines TNF- $\alpha$ and IL-1 $\beta$ compared with colonic DC 
A

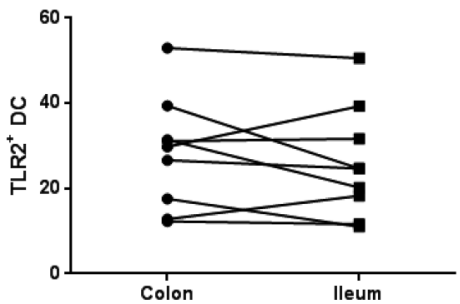

TLR4

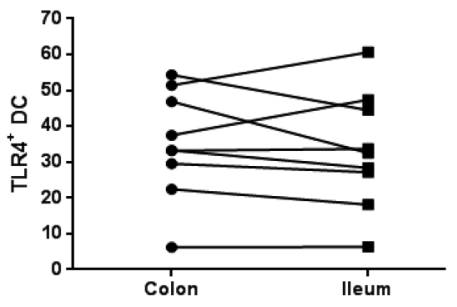

CD40

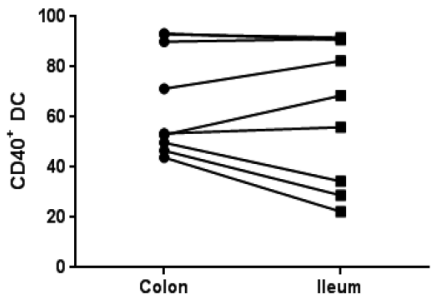

B Immature DC (short veils)

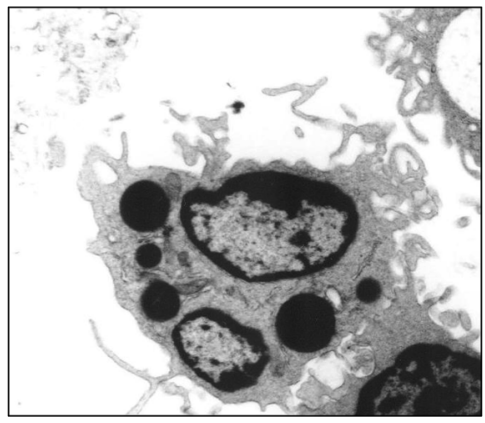

MФ/DC

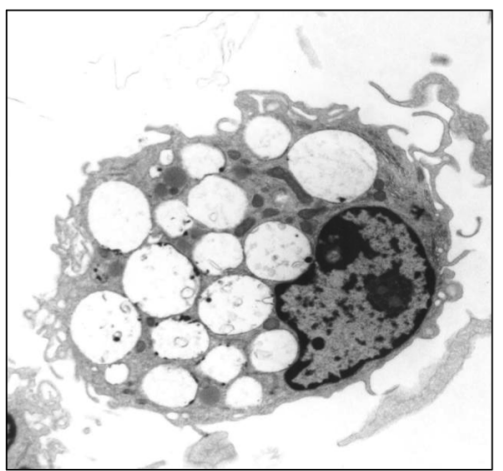

Mature DC (long veils)

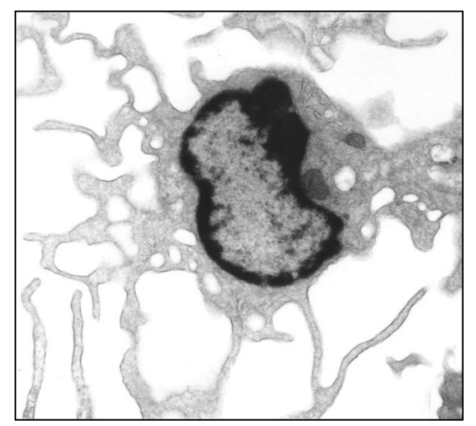

Types of APC

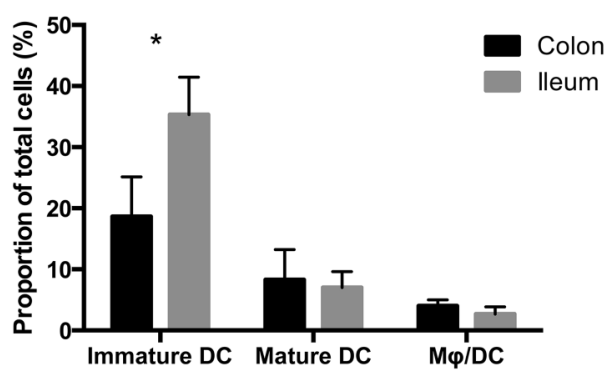

Figure 5 Dendritic cells (DC) maturation and activation in the colon and the ileum. (A) Summary graphs representing toll-like receptor 2 (TLR2) ( $n=9)$, TLR4 $(n=9)$ and CD40 $(n=8)$ expression on colonic and ileal DC, as assessed by flow cytometry $(n)$. (B) Electron micrograph pictures demonstrating types of DC present in the colon and the ileum: examples show short-veiled (immature) DC and long-veiled (mature) DC, and macrophage-like cells with an extensive vacuolar network. Cells were counted and types of $D C$ as a proportion of total cell numbers present was calculated and plotted on summary graph $(n=3)$. Paired t test was applied in all cases: ${ }^{*} p<0.05 ;{ }^{* *} p<0.01 ;{ }^{* * *} p<0.001$. APC, antigen-presenting cells.

(figure $6 \mathrm{~B}, \mathrm{C}$ ). These results suggest a more inflammatory role for ileal DC compared with colonic DC. There were no differences in production of TGF- $\beta$, IL-12, IL-23 or IL-22 (figure 6B). Further DC subsets were not analysed due to difficulties in obtaining sufficient cell numbers for culture \pm monensin to study cytokine production.

\section{Colonic DC have a greater potential to generate regulatory T cells compared with ileal DC}

We next determined whether the potentially greater regulatory properties of colonic DC compared with ileal DC and enhanced inflammatory cytokine production by ileal DC described above translated in their ability to generate $\mathrm{T}$ cell responses. We used total colonic or ileal DC (from the same individual) to stimulate allogeneic $\mathrm{CD}^{+} \mathrm{T}$ cell responses in vitro ( $\mathrm{T}$ cells isolated from the blood of a separate, healthy donor). Dividing $\mathrm{CD}^{+} \mathrm{T}$ cells were identified following DC co-culture as $\mathrm{CFSE}^{\mathrm{lo}} \mathrm{CD}^{+}$lymphocytes (figure $7 \mathrm{~A}$; pre-sorted as naive $\left(\mathrm{CD} 45 \mathrm{RO}^{--}\right) \mathrm{CD} 4^{+} \mathrm{T}$ cells prior to culture). Both colonic and ileal DC stimulated dose-dependent proliferation of CFSE-labelled T cells during
5 days of in vitro culture (figure 7A). We determined cytokine production and transcription factor (TF) expression from stimulated $\mathrm{T}$ cells post-culture and found that the predominant cytokines/TF produced by $\mathrm{T}$ cells stimulated by either colonic or ileal DC were IL-10 and T-bet (figure 7B). Although there were no differences in colonic or ileal DC ability to drive production of Th1/Th17 TF/cytokines measured (IFN- $\gamma$, TNF- $\alpha$, T-bet, IL-17A) or Th2/regulatory cytokines measured (IL-10, IL-4, TGF- $\beta$ ) (figure 7B), colonic DC generated a greater proportion of $\mathrm{CD} 4{ }^{+} \mathrm{FoxP}^{+}{ }^{+} \mathrm{IL}-10$-producing (regulatory) $\mathrm{T}$ cells compared with ileal DC (figure 7C). Taken with the regulatory properties of colonic DC described above, these data suggest colonic DC may play a greater role in intestinal immune tolerance compared with ileal DC.

Differential homing marker expression on colonic and ileal DC corresponds with their ability to imprint homing markers on $\mathrm{T}$ cells

In mice, $\mathrm{T}$ cells generated by intestinal $\mathrm{DC}$ expressed gut-homing marker $\alpha_{4} \beta_{7}$ and small-bowel-homing marker 
Figure 6 Intracellular cytokine production by colonic and ileal dendritic cells (DC). (A) FACS dot plots demonstrating production of interleukin (IL)-1 $\beta$, tumour necrosis factor (TNF)- $\alpha$, TGF- $\beta$ and IL-12 by colonic and ileal DC. Dot plot quadrants were set according to comparison with non-monensin controls. (B) Summary graph representing intracellular cytokine production by colonic and ileal DC (following monensin incubation) (TGF- $\beta$ : $n=7$; TNF- $\alpha: n=7 ;$ IL-12: $n=6$; IL-1 $\beta$ : $n=8$; IL-23: $n=3$; IL-22: $n=6$ ). (C) Summary graphs showing TNF- $\alpha$ $(n=7)$ and IL-1 $\beta(n=8)$ production by colonic and ileal DC. Paired t test was applied in all cases: ${ }^{*} \mathrm{p}<0.05$; ${ }^{* *} p<0.01 ;{ }^{* * *} p<0.001$.
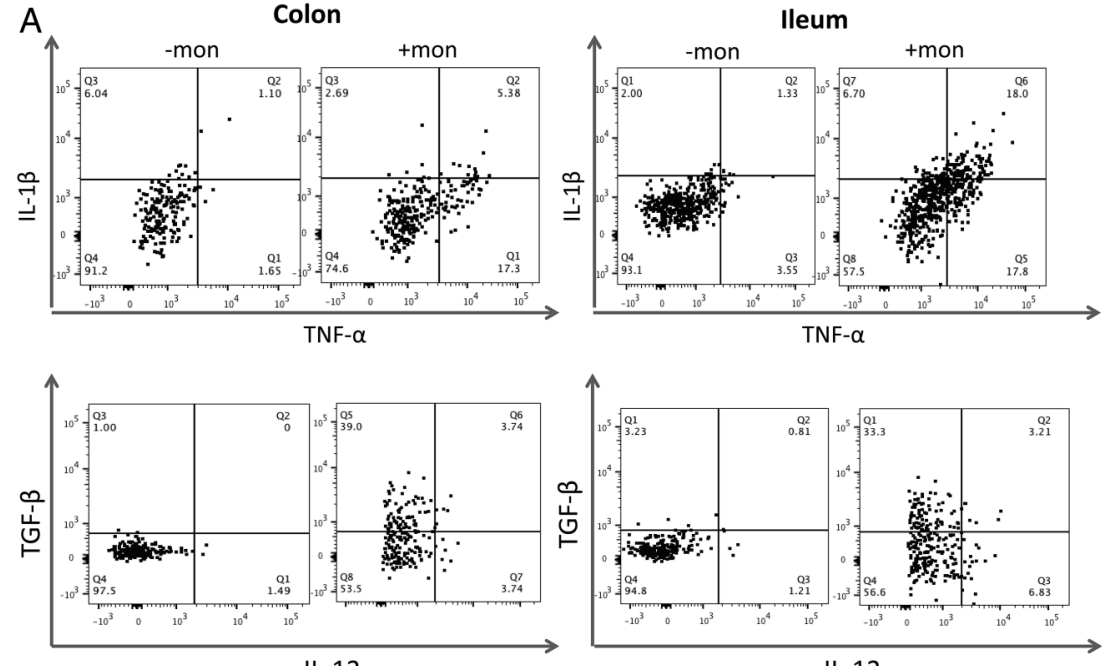

IL-12

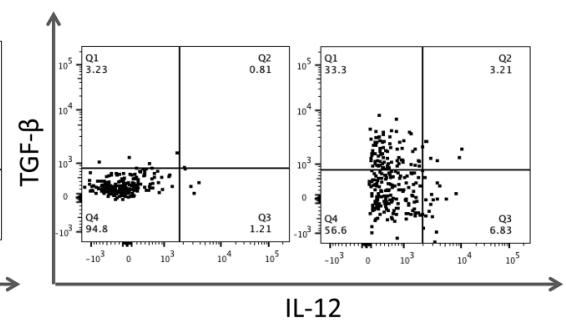

B

Intracellular cytokine production

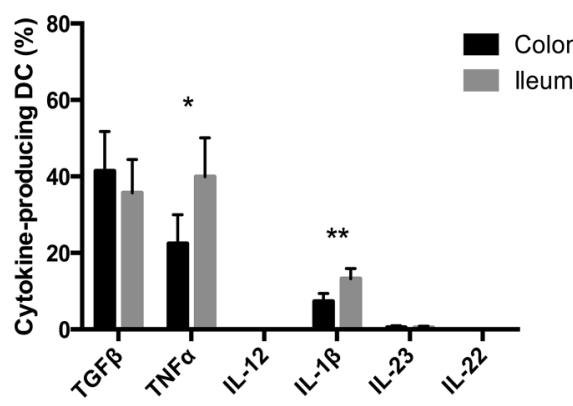

C
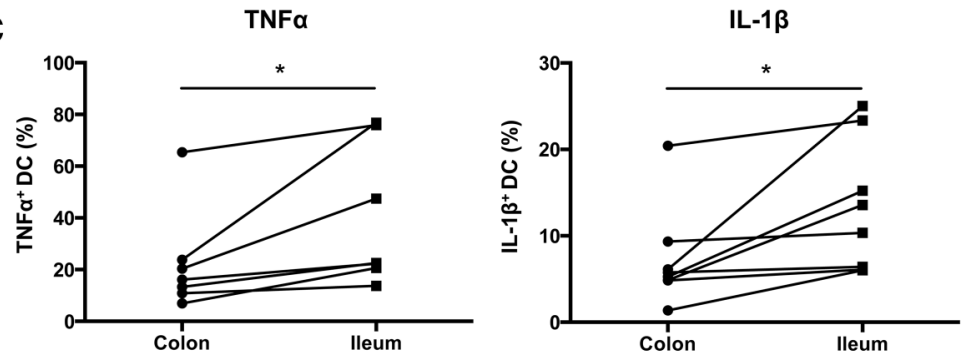

CCR9. ${ }^{6}{ }^{7}$ However, the majority of murine data involves DC derived from the small bowel or organised lymphoid tissue and data in humans are scarce. We have previously shown that human gut versus skin DC exhibit tissue-specific homing properties corresponding to their site of origin and the homing profile that they imprint on T cells. ${ }^{40}$ Here, we compared the homing receptor expression of colonic versus ileal DC and found that a greater proportion of colonic DC expressed the skin-associated homing marker CCR4 while their ileal counterparts preferentially expressed CCR9 (figure 8A). There was no change in expression of gut-homing marker $\beta 7$ integrin (data not shown). We then studied the ability of colonic and ileal DC to imprint these homing markers on naive $\mathrm{CD}^{+} \mathrm{T}$ cells. Ileal, but not colonic, DC were able to generate CCR9 ${ }^{+}$T cells; however, the majority of $\mathrm{T}$ cells generated in both cases were CCR9 ${ }^{-}$(figure $8 \mathrm{~B})$. Both ileal and colonic DC generated T cells expressing $\beta 7$ integrin (figure $8 \mathrm{C}$ ), but colonic DC were more able to imprint skin-homing marker CCR4 on T cells (figure 8D). These data demonstrate differential imprinting capacities of colonic and ileal DC that correspond to their own patterns of homing marker expression.

\section{DISCUSSION}

Our data demonstrate that specific functional differences exist between gut DC derived from the human colon and ileum. We demonstrate that regulatory properties of gut DC and their ability to imprint specific homing profiles on T cells are dependent upon their anatomical location within the gut. We demonstrate differences between colonic and ileal compartments in proportions and functions of human $\mathrm{CD} 103^{+}$DC subsets (which are a migratory DC subset critical for generation of T-regs and tolerance to the gut microbiota and food antigens in mice. ${ }^{12-15}$ ). Our data strongly suggest a more regulatory role for human colonic DC compared with their ileal counterparts, with lower proportions of colonic DC producing inflammatory cytokines and an enhanced ability to drive T-reg generation. Expression of the inhibitory receptor ILT3, high levels of which render APC tolerogenic, 3435 was also increased on colonic DC. Furthermore, we demonstrate that a greater proportion of colonic DC express the lymph-node-homing marker CCR7 and exhibit endocytic capacity, strongly suggesting that colonic DC have an enhanced ability to sample antigens and migrate to lymphoid tissue to generate regulatory immune responses 
Figure 7 Colonic and ileal dendritic cells (DC) ability to generate regulatory $T$ cells in vitro. (A) FACS dot plots demonstrating identification of stimulated/proliferating $\mathrm{CD}^{+}$naive T cells following 5-day co-culture with DC, via gating on blasting lymphocytes from forward scatter versus side scatter plot, and subsequent gating of $\mathrm{CD}^{+}{ }^{+}$CFSE ${ }^{\text {lo }}$ cells (cells were pre-sorted prior to culture as $\mathrm{CD} 4^{+}$naive T cells). $T$ cell proliferation displayed as mean \pm SEM proportion of dividing T cells. Concentration of DC was statistically significant following two-way analysis of variance analysis ( $p<0.001 ; n=7)$.

(B) FACS plots demonstrating expression of interleukin (IL)-10 and T-bet by dividing T cells (CD3 ${ }^{+}$CFSE ${ }^{\text {lo }}$ post-culture, sorted pre-culture as $\mathrm{CD} 4^{+}$naive T cells) following culture: quadrants were set based on isotype-matched control (T-bet) or non-monensin control (IL-10). Summary graph showing mean \pm SEM proportions of diving T cells producing/ expressing T-bet $(n=6)$, tumour necrosis factor (TNF)- $\alpha(n=5)$, IFN- $\gamma$ $(n=7), I L-17 A(n=7), I L-10(n=7)$, TGF- $\beta 1(n=7)$ and IL-4 $(n=7)$. (C) FACS plots showing dividing $T$ cells (CD3 $^{+}$CFSE $^{\text {lo }}$ post-culture, sorted pre-culture as $\mathrm{CD} 4^{+}$naive T cells) expressing FoxP3 and producing IL-10 following stimulation by either colonic or ileal DC. Summary graph showing all experiments $(n=7)$. Quadrants on dot plots were set based on isotype-matched control (FoxP3) or non-monensin control (IL-10). Paired $t$ test was applied in all cases: ${ }^{*} p<0.05$; ${ }^{* *} p<0.01 ;{ }^{* * *} p<0.001$. CFSE, carboxyfluorescein diacetate succinimidyl.
A Blasting lymphocytes

Dividing T-cells
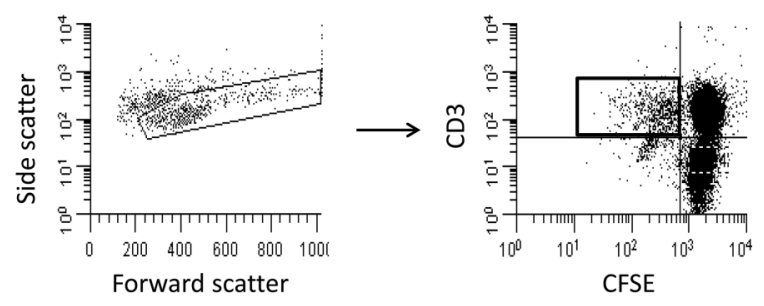

DC stimulatory capacity
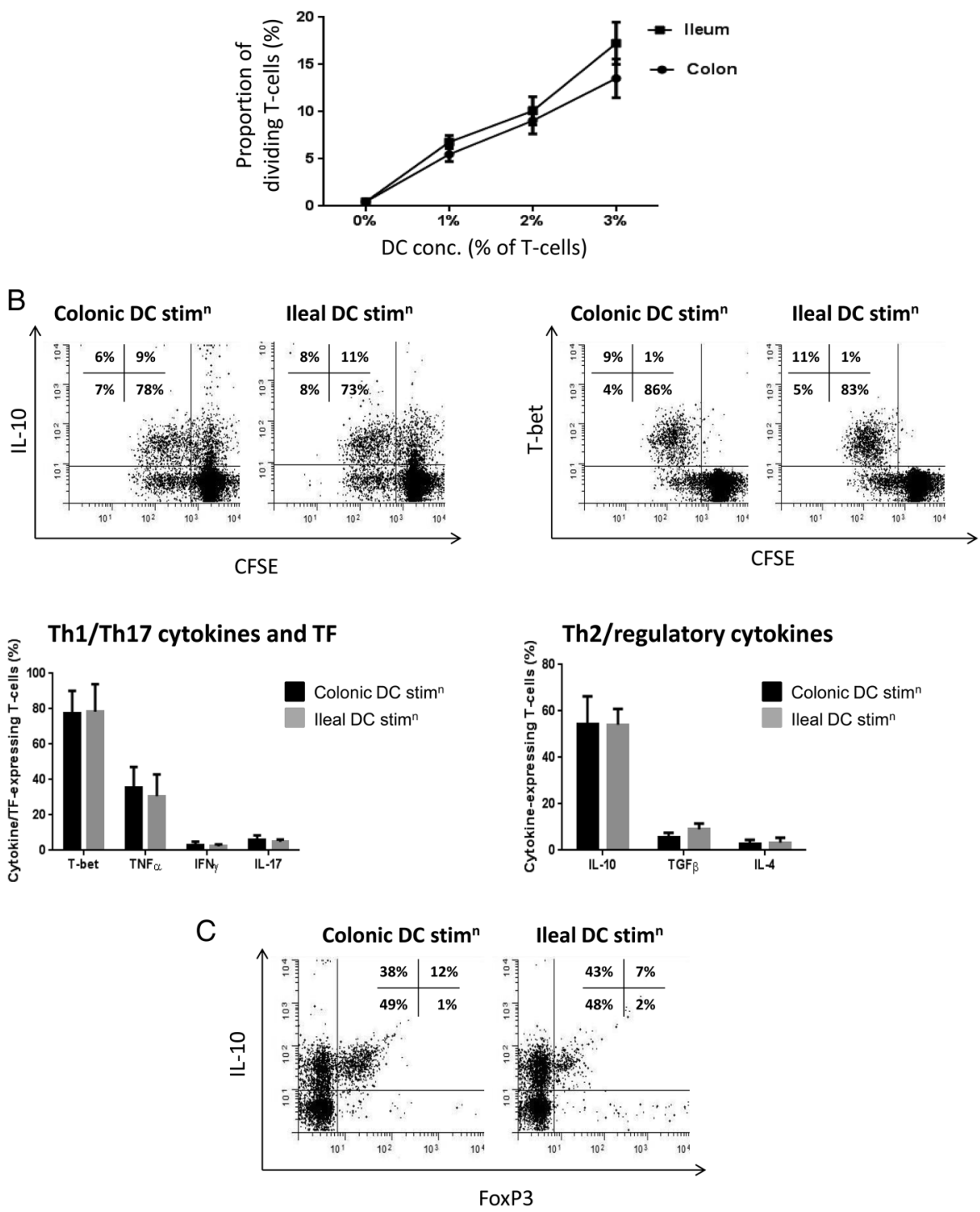

Regulatory T-cells

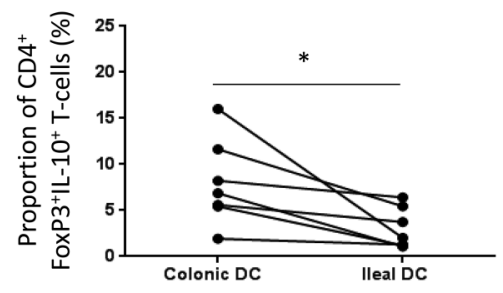


Figure 8 Colonic and ileal dendritic cells (DC) ability to imprint homing markers on T cells. (A) FACS dot plots demonstrating expression of CCR4 and CCR9 on DC from the colon and the ileum (pre-gated on $\mathrm{CD}^{4} 5^{+}$viable cells and then HLA-DR ${ }^{+}$lineage ${ }^{-}$cells). Summary graphs showing CCR4 and CCR9 expression by colonic and ileal $D C(n=4)$. (B) FACS dot plots showing examples of CCR9 expression on dividing T cells $\left(\mathrm{CD}^{+}{ }^{+} \mathrm{CFSE} \mathrm{E}^{\mathrm{lo}}\right.$ post-culture, sorted pre-culture as $\mathrm{CD}^{+}$naive T cells) following stimulation by colonic or ileal DC, and summary graph showing all experiments $(n=7)$. (C) FACS dot plots showing examples of $\beta 7$ integrin expression on dividing $T$ cells $\left(\right.$ CD3 $^{+}$CFSE $^{\text {lo }}$ post-culture, sorted pre-culture as CD4 ${ }^{+}$naive T cells) following stimulation by colonic or ileal $D C$, and summary graph showing all experiments $(n=7)$. (D) FACS dot plots showing examples of CCR4 expression on dividing $T$ cells $\left(\mathrm{CD}^{+}{ }^{+} \mathrm{CFSE}^{\text {lo }}\right.$ post-culture, sorted pre-culture as $\mathrm{CD}^{+}$naive T cells) following stimulation by colonic or ileal $D C$, and summary graph showing all experiments $(n=7)$. Quadrants on dot plots were set based on isotype-matched controls. Paired t test was applied in all cases: ${ }^{*} p<0.05$; ${ }^{* *} p<0.01 ;{ }^{* * *} p<0.001$.
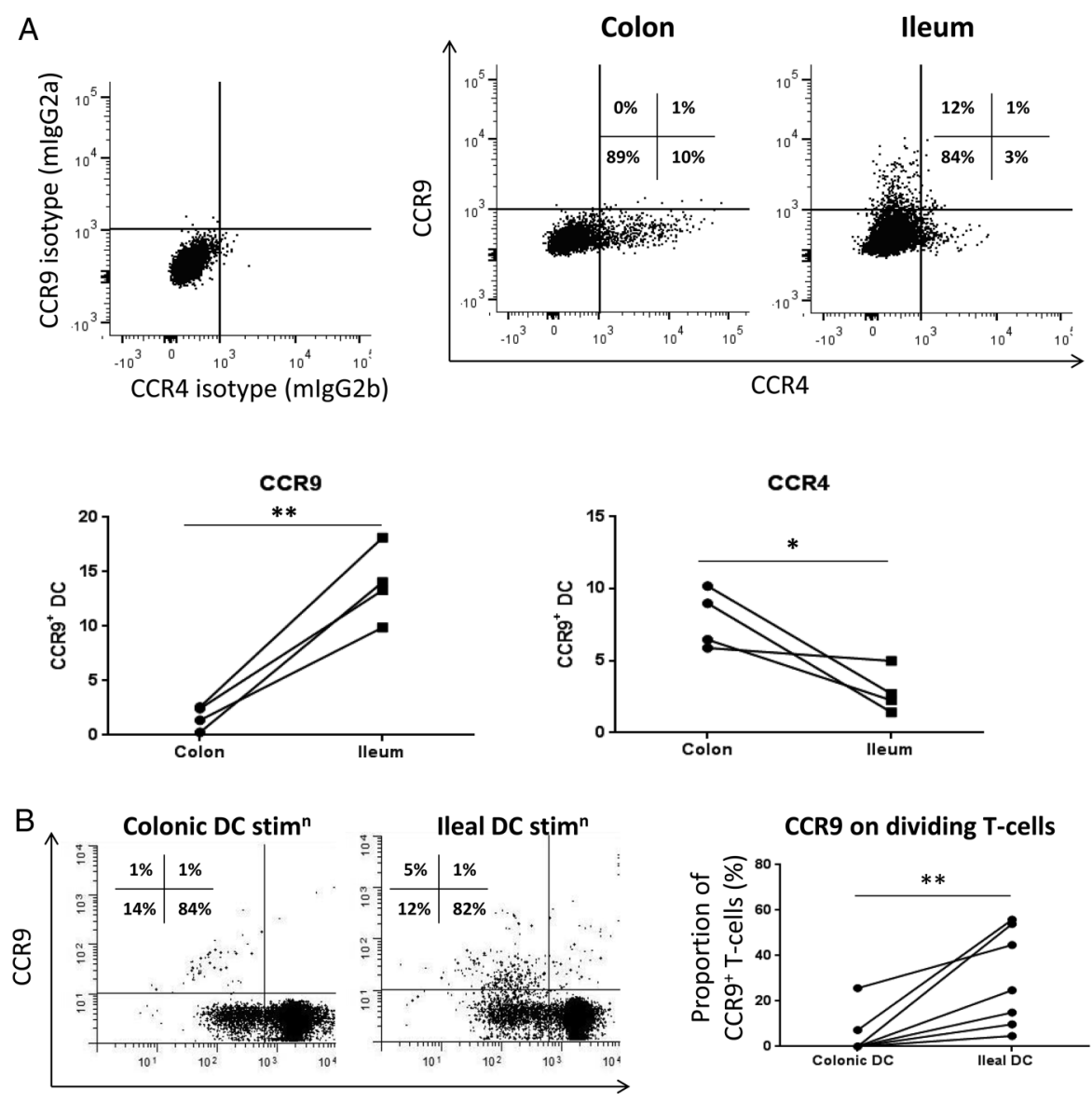

CFSE
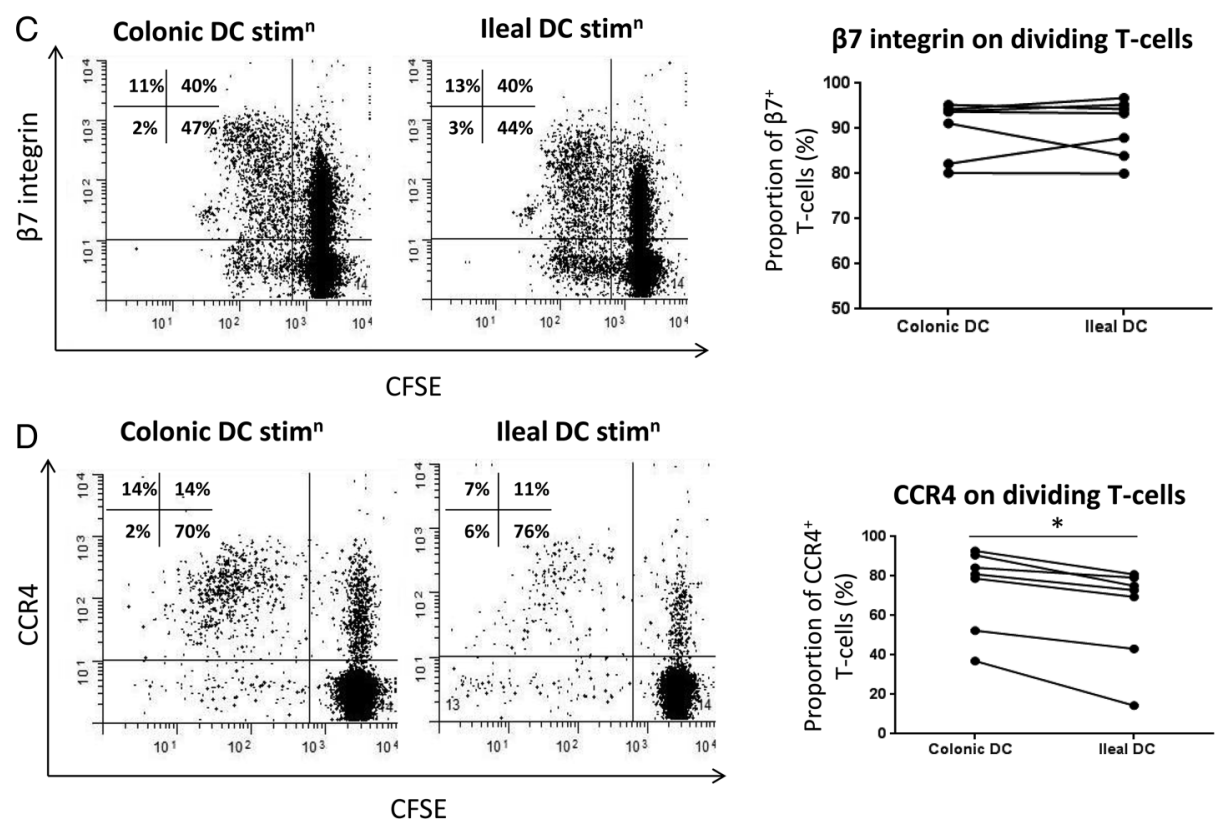

CFSE

in vivo, compared with ileal DC. Such a function may be important in generating tolerance to the gut microbiota, the load of which is greatly elevated in the colon versus the ileum. Despite the differences both in function and bacterial load of the colon and the ileum, few studies distinguish between immune cells in colonic and ileal compartments, and functional information in humans is scarce in both compartments. Our new data demonstrate that the colon and the ileum should be regarded as separate entities, each comprising DC with distinct roles in gut immunity.

Identification of intestinal DC in any species is challenging due to the use of markers that do not discriminate clearly between DC and macrophages (M $\Phi),{ }^{27}$ and also complicated by the use of different markers by different laboratories to identify APC. Here, we show successful characterisation of human intestinal DC and have confirmed they do not express macrophage 
markers. We have determined that in the steady state both human colonic and ileal DC expressed CD103, a DC subset with tolerogenic properties in mice. ${ }^{41-43}$ The majority of $\mathrm{CD}_{103}{ }^{+}$DC in both intestinal compartments co-expressed Sirpo, the human equivalent of murine $\mathrm{CD} 103^{+} \mathrm{CD} 11 \mathrm{~b}^{+}$ DC. ${ }^{22} 24$ However, there was a greater proportion of the double-positive $\mathrm{CD} 103^{+} \mathrm{Sirp}^{+}$DC subset in the ileum, while there were greater proportions of single-positive CD $103^{+}$Sirp $\alpha^{-}$ DC (human equivalent of murine $\mathrm{CD} 103^{+} \mathrm{CD} 11 \mathrm{~b}^{-} \mathrm{DC}$ ) in the colon relative to the ileum (despite $\mathrm{CD}_{103}{ }^{+} \mathrm{Sirp}^{+} \mathrm{DC}$ still being the predominant subset), reflecting patterns of expression of CD103 and CD11b in mice. ${ }^{21} 44 \mathrm{~A}$ striking difference between this murine and our human data however is illustrated by the predominant $\mathrm{DC}$ subset in the murine colon being $\mathrm{CD}_{103}{ }^{+} \mathrm{CD} 11 \mathrm{~b}^{-}$DC in mice. ${ }^{44}$ While in humans we show there are indeed greater proportions of their $\mathrm{CD} 103^{+} \mathrm{Sirp} \alpha^{-}$ DC equivalents in the colon, this subset is still a minority subset in the human colon and certainly not the predominant DC subset. The significance of the increased proportions of these DC in the colon remains to be determined. Although recent studies suggest both murine $\mathrm{CD} 103^{+} \mathrm{CD} 11 \mathrm{~b}^{+}$and $\mathrm{CD} 103^{+} \mathrm{CD} 11 \mathrm{~b}^{-}$DC subsets may have distinct roles in intestinal immune homeostasis (reviewed in ${ }^{20}$ ), the specific regulatory functions of these $\mathrm{CD}_{103^{+}}$subsets and their human equivalents are unclear. The essential role for murine $\mathrm{CD} 103^{+} \mathrm{CD} 11 \mathrm{~b}^{+} \mathrm{DC}$ in Th17 cell polarisation ${ }^{22}$ may suggest a greater proportion of DC in the human ileum may generate Th17 responses. However, other studies have shown human $\mathrm{CD}_{103}{ }^{+} \mathrm{Sirp}^{+}{ }^{+} \mathrm{DC}$ are better than their CD $103^{+}$Sirp $\alpha^{-}$counterparts at generating regulatory $\mathrm{T}$ cell responses in vitro. ${ }^{24}$ Further functional studies are necessary to determine the roles of murine and human $\mathrm{CD}_{103^{+}}$DC subsets in mucosal immune homeostasis and whether the functions of these subsets may be altered under inflammatory conditions compared with the steady state.

Although the low numbers of cells available from human biopsy tissue did not allow us to further characterise $\mathrm{CD}_{103}{ }^{+} \mathrm{Sirp} \alpha^{-}$DC, we demonstrate compartment-specific differences in specific DC subsets including CD103-(Sirpo $\left.{ }^{+}\right)$and $\mathrm{CD}_{103}{ }^{+}$Sirp $\alpha^{+}$DC (as well as total CD $103^{+}$DC). Proportions of these subsets expressing CCR7 were increased in the colon, strongly suggesting a more migratory role for colonic DC. Properties of gut DC in the steady state include a high endocytic capacity due to continual sampling of antigens from the gut lumen. ${ }^{11}$ We observed that human DC contained a greater endocytic capacity in the colon versus the ileum. Taken together, the enhanced migratory potential and endocytic capacity of colonic DC compared with ileal DC, along with their enhanced potential to generate T-regs, may be representative of a regulatory profile for DC in the colon. These differences between colonic and ileal DC subsets were the most striking in $\mathrm{CD} 103^{+} \mathrm{Sirp} \alpha^{+}$ DC, with nearly all of this DC subset in the colon being endocytic and comprising the majority of endocytic DC in either compartment. Only few CD103- ${ }^{-}$DC displayed endocytic capacity, supporting recent studies in mice. ${ }^{45}$ These data support previous studies demonstrating high levels of CCR7 expression on human $\mathrm{CD} 03^{+}$Sirp ${ }^{+}$DC from the ileum ${ }^{24}$ and suggest an important role for this DC subset in antigen sampling leading to generation of T-reg responses that may be directed against the gut microbiota in the steady state. The major phagocytic role of $\mathrm{CX}_{3 \mathrm{CR}} 1^{+}$mononuclear phagocytes, but not $\mathrm{CD}_{103^{+}} \mathrm{DC}$, during antigen-driven colitis in mice ${ }^{46}$ suggests $\mathrm{CD}_{103^{+}} \mathrm{DC}^{-}$ may lose endocytic capacity under inflammatory conditions.

The inhibitory receptor ILT3 was expressed on all DC subsets in both colon and ileum to some extent. However, a greater proportion of all DC subsets expressed ILT3 in the colon versus the ileum, supporting a regulatory role for colonic DC. However, a much greater proportion of CD103- DC expressed this receptor and at higher levels than $\mathrm{CD}_{103^{+}} \mathrm{DC}$. Furthermore, differences in proportions of ILT3 ${ }^{+}$DC between the colon and the ileum were the most striking on the CD103$\left(\operatorname{Sirp} \alpha^{+}\right)$DC subset, on which levels of ILT3 per cell were also enhanced. Given the association of high levels of ILT3 with tolerogenic APC properties, ${ }^{25} 26$ these data suggest a novel role for $\mathrm{CD}_{103^{-}} \mathrm{DC}$ in intestinal immune tolerance in the steady state. Although data regarding the homeostatic functions of intestinal DC have been predominantly focused on $\mathrm{CD} 103^{+}$DC, recent murine studies demonstrate $\mathrm{CD} 103^{-} \mathrm{CD} 11 \mathrm{~b}^{+} \mathrm{DC}$ (equivalent to human $\mathrm{CD}_{103^{-}} \mathrm{Sirp}^{+}$DC) expressing CXCL16 may indeed play a protective role in the gut mucosa via induction of IL-22 (a cytokine critical for tissue regeneration and recovery following infection and inflammation). ${ }^{47}$ We demonstrate that the majority of human $\mathrm{CD}_{103^{-}} \mathrm{DC}$ in both colonic and ileal compartments, like CD $103^{+}$DC, expressed CCR7, suggesting they are a migratory cell subset. These data support murine studies that demonstrate CD103- ${ }^{-}$C migration in afferent lymph. ${ }^{48}$

Our data demonstrate intrinsic differences in specific DC subsets in the colon versus the ileum, supporting a more regulatory role for colonic DC. Indeed, the reduced proportion of colonic DC producing pro-inflammatory TNF- $\alpha$ and IL- $\beta$, combined with the enhanced ability of colonic DC to generate $\mathrm{CD} 4{ }^{+} \mathrm{FoxP}^{+}{ }^{\mathrm{IL}}-10^{+}$T-reg in vitro, strongly support a more regulatory role for colonic DC compared with their ileal counterparts. Of note, TLR expression and cytokine production was inherently low by DC in all cases, with only TGF- $\beta$, TNF- $\alpha$ and IL-1 $\beta$ being produced at detectable levels. Even in these cases, cytokine-producing (and $\mathrm{TLR}^{+}$) DC comprised only the minority of DC and there were little effects of lipopolysaccharide stimulation at various doses (data not shown), supporting studies demonstrating intestinal DC are hyporesponsive to stimulation and involved in intestinal immune tolerance. ${ }^{9} 101249$ The higher proportions of morphologically immature DC in the ileum as detected by EM may be reflective of the reduced bacterial load in this intestinal compartment.

Murine DC from intestinal organised lymphoid tissue imprint gut-homing markers $\alpha_{4} \beta_{7}$ and CCR9 on T cells from different sources, thus targeting $\mathrm{T}$ cells back to intestinal tissue. ${ }^{6-8}$ We previously demonstrated human gut DC generate gut-specific T cell responses. ${ }^{40}$ However, there was previously no information available regarding compartment-specific effects of gut DC on T cell stimulation or regarding the homing properties of the DC themselves. We demonstrate here that colonic and ileal DC exhibit distinct patterns of homing marker expression in terms of chemokine receptors CCR9 (small bowel homing) and CCR4 (skin homing). Furthermore, chemokine receptor expression on colonic and ileal DC corresponded to their ability to imprint these same receptors on stimulated $\mathrm{T}$ cells, with an enhanced ability of ileal DC to generate $\operatorname{CCR} 9^{+}\left(\beta 7^{+}\right)$T cells compared with colonic DC, while colonic DC imprinted CCR4 on T cells. The differences in ileal and colonic DC ability to imprint homing markers on T cells (including enhanced ability of colonic DC to generate skin-homing CCR $4^{+} \mathrm{T}$ cells) have implications in IBD with tissue compartmentalisation. Both Crohn's disease and ulcerative colitis are associated with increased infiltrating gut-homing lymphocytes. ${ }^{50} 51$ Indeed, treatment with anti-guthoming $\alpha 4 \beta 7$ therapy is effective in some patients with IBD. ${ }^{52}$ Furthermore, some patients with IBD have a propensity to develop extraintestinal manifestations affecting the skin, ${ }^{53}$ as well as anti-TNF-induced psoriasiform skin lesions mediated by DC 
in some cases. ${ }^{54}$ Further studies may determine whether patients with IBD with colonic inflammation as opposed to ileal inflammation are more likely to develop skin manifestations such as erythema nodosum and pyoderma gangrenosum. Together, our data demonstrate, for the first time, that functional differences exist between human intestinal DC within colonic and ileal compartments of the gut. It can be speculated that the more extensive bacterial load in the colon compared with the ileum ${ }^{25}{ }^{26}$ requires colonic APC to adopt regulatory properties, preventing unwanted immune responses to the gut microbiota. However, further studies are necessary to determine the role of the gut microbiota in colonic and ileal compartments in shaping DC function. These data provide new insight into the regulatory functions and properties of $\mathrm{CD}_{103}{ }^{+}$and $\mathrm{CD}_{103^{-}}$gut DC subsets in the steady state. Targeting factors that determine the activation or inflammatory state of intestinal DC within separate gut compartments may allow manipulation and generation of regulatory DC, aimed at immunomodulatory therapy for inflammatory disease with tissue compartmentalisation.

Acknowledgements This research was funded by St. Mark's Foundation (Harrow, UK), The Biotechnology and Biological Sciences Research Council (BBSRC; BB/ J004529/1) and The National Institutes of Health (NIH; US) including The National Institute of Diabetes and Digestive and Kidney Diseases (NIH/NIDDK; T32-DK07632 and P01-DK072084) and The National Institute of Allergy and Infectious Disease (NIH/NIAID; R21-AI094033). We also gratefully acknowledge funding support from The Harvey M. and Lyn P. Meyerhoff Inflammatory Bowel Disease Centre at The Johns Hopkins Hospital, Baltimore, US.

Contributors ERM was involved in study concept and design, acquisition, analysis and interpretation of data, drafting, revision of manuscript and statistical analysis. $D B, H O A-H$ and NRE were involved in data acquisition/analysis, interpretation of data and revision of manuscript. JL, STCP, HS, RM, TRE, GHL, AP, SRB and ML were involved in critical material and reagent support, data interpretation and revision of manuscript. SCK, XL and ALH were involved in study concept and design, interpretation of data, revision of manuscript and study supervision and obtaining ethical approval.

\section{Competing interests None.}

Ethics approval Outer West London Regional Ethics Committee and Imperial College London (08/H0717/24).

Provenance and peer review Not commissioned; externally peer reviewed.

Open Access This is an Open Access article distributed in accordance with the Creative Commons Attribution Non Commercial (CC BY-NC 4.0) license, which permits others to distribute, remix, adapt, build upon this work non-commercially, and license their derivative works on different terms, provided the original work is properly cited and the use is non-commercial. See: http://creativecommons.org/ licenses/by-nc/4.0

\section{REFERENCES}

1 Scott CL, Aumeunier AM, Mowat AM. Intestinal CD103+ dendritic cells: master regulators of tolerance? Trends Immunol 2011;32:412-19.

2 Banchereau J, Steinman RM. Dendritic cells and the control of immunity. Nature 1998:392:245-2.

3 Macpherson AJ, Uhr T. Induction of protective IgA by intestinal dendritic cells carrying commensal bacteria. Science 2004;303:1662-5.

4 Voedisch S, Koenecke C, David S, et al. Mesenteric lymph nodes confine dendritic cell-mediated dissemination of Salmonella enterica serovar Typhimurium and limit systemic disease in mice. Infect Immun 2009;77:3170-80.

5 Mann ER, Landy JD, Bernardo D, et al. Intestinal dendritic cells: their role in intestinal inflammation, manipulation by the gut microbiota and differences between mice and men. Immunol Lett 2013;150:30-40.

6 Stagg AJ, Kamm MA, Knight SC. Intestinal dendritic cells increase T cell expression of alpha4beta7 integrin. Eur J Immunol 2002;32:1445-54.

7 Mora JR, Bono MR, Manjunath N, et al. Selective imprinting of gut-homing T cells by Peyer's patch dendritic cells. Nature 2003;424:88-93.

8 Johansson-Lindbom B, Svensson M, Wurbel MA, et al. Selective generation of gut tropic T cells in gut-associated lymphoid tissue (GALT): requirement for GALT dendritic cells and adjuvant. J Exp Med 2003;198:963-9.

9 Coombes $\mathrm{JL}$, Powrie F. Dendritic cells in intestinal immune regulation. Nat Rev Immunol 2008:8:435-46.

10 Chirdo FG, Millington OR, Beacock-Sharp $\mathrm{H}$, et al. Immunomodulatory dendritic cells in intestinal lamina propria. Eur J Immunol 2005;35:1831-40.
11 Hart AL, Al-Hassi HO, Rigby RJ, et al. Characteristics of intestinal dendritic cells in inflammatory bowel diseases. Gastroenterology 2005;129:50-65.

12 Coombes JL, Maloy KJ. Control of intestinal homeostasis by regulatory T cells and dendritic cells. Semin Immunol 2007:19:116-26.

13 Worbs T, Bode U, Yan S, et al. Oral tolerance originates in the intestinal immune system and relies on antigen carriage by dendritic cells. J Exp Med 2006;203:519-27.

14 Jaensson $E$, Uronen-Hansson $H$, Pabst O, et al. Small intestinal CD103+ dendritic cells display unique functional properties that are conserved between mice and humans. J Exp Med 2008;205:2139-49.

15 Schulz 0, Jaensson E, Persson EK, et al. Intestinal CD103+, but not CX3CR1+, antigen sampling cells migrate in lymph and serve classical dendritic cell functions. J Exp Med 2009;206:3101-14.

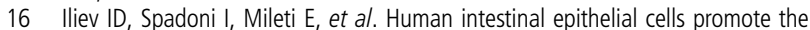
differentiation of tolerogenic dendritic cells. Gut 2009;58:1481-9.

17 Matteoli G, Mazzini E, lliev ID, et al. Gut CD103+ dendritic cells express indoleamine 2,3-dioxygenase which influences $\mathrm{T}$ regulatory/T effector cell balance and oral tolerance induction. Gut 2010:59:595-604.

18 Diegelmann J, Olszak T, Goke B, et al. A novel role for interleukin-27 (IL-27) as mediator of intestinal epithelial barrier protection mediated via differential signal transducer and activator of transcription (STAT) protein signaling and induction of antibacterial and anti-inflammatory proteins. J Biol Chem 2012:287:286-98.

19 Miller JC, Brown BD, Shay T, et al. Deciphering the transcriptional network of the dendritic cell lineage. Nat Immunol 2012;13:888-99.

20 Cerovic V, Bain CC, Mowat AM, et al. Intestinal macrophages and dendritic cells: what's the difference? Trends Immunol 2014;35:270-7.

21 Persson EK, Scott CL, Mowat AM, et al. Dendritic cell subsets in the intestinal lamina propria: ontogeny and function. Eur J Immunol 2013:43:3098-107.

22 Persson EK, Uronen-Hansson $\mathrm{H}$, Semmrich $\mathrm{M}$, et al. IRF4 transcription-factordependent CD103(+)CD11b(+) dendritic cells drive mucosal Thelper 17 cell differentiation. Immunity 2013;38:958-69.

23 Poulin LF, Reyal Y, Uronen-Hansson H, et al. DNGR-1 is a specific and universal marker of mouse and human Batf3-dependent dendritic cells in lymphoid and nonlymphoid tissues. Blood 2012;119:6052-62.

24 Watchmaker PB, Lahl K, Lee $\mathrm{M}$, et al. Comparative transcriptional and functional profiling defines conserved programs of intestinal DC differentiation in humans and mice. Nat Immunol 2014;15:98-108.

25 Simon GL, Gorbach SL. The human intestinal microflora. Dig Dis Sci 1986; 31(9 Suppl):147S-62S

26 Quigley EM, Quera R. Small intestinal bacterial overgrowth: roles of antibiotics, prebiotics, and probiotics. Gastroenterology 2006;130(2 Suppl 1):S78-90.

27 Persson EK, Jaensson E, Agace WW. The diverse ontogeny and function of murine small intestinal dendritic cell/macrophage subsets. Immunobiology 2010;215: 692-7.

28 Varol C, Zigmond E, Jung S. Securing the immune tightrope: mononuclear phagocytes in the intestinal lamina propria. Nat Rev Immunol 2010;10:415-26.

29 Bain CC, Scott CL, Uronen-Hansson H, et al. Resident and pro-inflammatory macrophages in the colon represent alternative context-dependent fates of the same Ly6Chi monocyte precursors. Mucosal Immunol 2013;6:498-510.

30 Niess JH, Brand S, Gu X, et al. CX3CR1-mediated dendritic cell access to the intestinal lumen and bacterial clearance. Science 2005;307:254-8.

31 Bogunovic $M$, Ginhoux $F$, Helft J, et al. Origin of the lamina propria dendritic cell network. Immunity 2009:31:513-25.

32 Bell SJ, Rigby R, English N, et al. Migration and maturation of human colonic dendritic cells. J Immunol 2001;166:4958-67.

33 Cella M, Dohring C, Samaridis J, et al. A novel inhibitory receptor (ILT3) expressed on monocytes, macrophages, and dendritic cells involved in antigen processing. J Exp Med 1997;185:1743-51.

34 Chang CC, Ciubotariu R, Manavalan JS, et al. Tolerization of dendritic cells by $\mathrm{T}(\mathrm{S})$ cells: the crucial role of inhibitory receptors ILT3 and ILT4. Nat Immunol 2002:3:237-43

35 Svajger U, Vidmar A, Jeras M. Niflumic acid renders dendritic cells tolerogenic and up-regulates inhibitory molecules ILT3 and ILT4. Int Immunopharmacol 2008:8:997-1005.

36 Suciu-Foca N, Feirt N, Zhang QY, et al. Soluble Ig-like transcript 3 inhibits tumor allograft rejection in humanized SCID mice and T cell responses in cancer patients. J Immunol 2007;178:7432-41.

37 Vlad G, D'Agati VD, Zhang QY, et al. Immunoglobulin-like transcript 3-Fc suppresses T-cell responses to allogeneic human islet transplants in hu-NOD/SCID mice. Diabetes 2008;57:1878-86

38 Al-Hassi HO, Mann ER, Sanchez B, et al. Altered human gut dendritic cell properties in ulcerative colitis are reversed by Lactobacillus plantarum extracellular encrypted peptide STp. Mol Nutr Food Res 2014;58:1132-43.

39 Maroof A, English NR, Bedford PA, et al. Developing dendritic cells become 'lacy' cells packed with fat and glycogen. Immunology 2005;115:473-83.

40 Mann ER, Bernardo D, Al-Hassi HO, et al. Human gut-specific homeostatic dendritic cells are generated from blood precursors by the gut microenvironment. Inflamm Bowel Dis 2012;18:1275-86. 


\section{Gut immunity}

41 Coombes JL, Siddiqui KR, Arancibia-Carcamo CV, et al. A functionally specialized population of mucosal CD103+ DCs induces Foxp3+ regulatory T cells via a TGF-beta and retinoic acid-dependent mechanism. J Exp Med 2007;204:1757-64.

42 Sun CM, Hall JA, Blank RB, et al. Small intestine lamina propria dendritic cells promote de novo generation of Foxp3T reg cells via retinoic acid. J Exp Med 2007;204:1775-85.

43 Annacker O, Coombes JL, Malmstrom V, et al. Essential role for CD103 in the T cell-mediated regulation of experimental colitis. J Exp Med 2005;202:1051-61.

44 Denning TL, Norris BA, Medina-Contreras 0 , et al. Functional specializations of intestinal dendritic cell and macrophage subsets that control Th17 and regulatory $T$ cell responses are dependent on the T cell/APC ratio, source of mouse strain, and regional localization. J Immunol 2011;187:733-47.

45 Scott CL, Bain CC, Wright PB et al. CCR2CD103 intestinal dendritic cells develop from DC-committed precursors and induce interleukin-17 production by $T$ cells. Mucosal Immunol Published Online First: 20 Aug 2014.

46 Rossini V, Zhurina D, Radulovic K, et al. CX3CR1(+) cells facilitate the activation of CD4T cells in the colonic lamina propria during antigen-driven colitis. Mucosal Immunol 2014;7:533-48.

47 Satoh-Takayama N, Serafini N, Verrier T, et al. The Chemokine Receptor CXCR6 Controls the Functional Topography of Interleukin-22 Producing Intestinal Innate Lymphoid Cells. Immunity 2014;41:776-88.
48 Cerovic V, Houston SA, Scott CL, et al. Intestinal CD103(-) dendritic cells migrate in lymph and prime effector T cells. Mucosal Immunol 2013;6: 104-13.

49 Mowat AM, Bain CC. Mucosal macrophages in intestinal homeostasis and inflammation. J Innate Immun 2011;3:550-64.

50 Hart AL, Kamm MA, Knight SC, et al. Prospective evaluation of intestinal homing memory T cells in ulcerative colitis. Inflamm Bowel Dis 2004;10: 496-503.

51 Hart AL, Kamm MA, Knight SC, et al. Quantitative and functional characteristics of intestinal-homing memory T cells: analysis of Crohn's disease patients and healthy controls. Clin Exp Immunol 2004;135:137-45.

52 Parikh A, Leach T, Wyant $\mathrm{T}$, et al. Vedolizumab for the treatment of active ulcerative colitis: a randomized controlled phase 2 dose-ranging study. Inflamm Bowel Dis 2012;18:1470-9.

53 Trost $\mathrm{LB}, \mathrm{McD}$ onnell JK. Important cutaneous manifestations of inflammatory bowel disease. Postgrad Med J 2005;81:580-5.

54 Tillack C, Ehmann LM, Friedrich M, et al. Anti-TNF antibody-induced psoriasiform skin lesions in patients with inflammatory bowel disease are characterised by interferon-gamma-expressing Th1 cells and IL-17A/IL-22-expressing Th17 cells and respond to anti-IL-12/IL-23 antibody treatment. Gut 2014;63:567-7. 